\title{
Preconceptual design of a fluoride high temperature salt-cooled engineering demonstration
}

\section{reactor: core design and safety analysis}

Nicholas R. Brown, ${ }^{1,2, ~}{ }^{*}$ Benjamin R. Betzler, ${ }^{1}$ Juan J. Carbajo, ${ }^{1}$ Aaron J. Wysocki, ${ }^{1}$ M. Scott Greenwood, ${ }^{1}$ Cole Gentry, ${ }^{1}$ A. Louis Qualls ${ }^{1}$

${ }^{1}$ Oak Ridge National Laboratory: Building 5700, MS-6165, Oak Ridge, TN, 37830, USA

2 The Pennsylvania State University, 229 Reber Building, University Park, PA 16802, USA (present affiliation)

*Corresponding author: Nicholas R. Brown, nrb26@psu.edu

\section{ABSTRACT}

Engineering demonstration reactors are nuclear reactors built to establish proof of concept for technology options that have never been built. Examples of engineering demonstration reactors include Peach Bottom 1 for high temperature gas-cooled reactors (HTGRs) and Experimental Breeder Reactor II (EBR-II) for sodium-cooled fast reactors. Engineering demonstrations have historically played a vital role in advancing the technology readiness level of reactor technologies. This paper details a preconceptual design for a fluoride salt-cooled engineering demonstration reactor. The fluoride salt-cooled high-temperature reactor (FHR) demonstration reactor (DR) is a concept for a salt-cooled reactor with 100 megawatts of thermal output (MWt). It would use tristructural-isotropic (TRISO) particle fuel within prismatic graphite blocks. FLiBe $\left(2{ }^{7} \mathrm{LiF}_{-} \mathrm{BeF}_{2}\right)$ is the reference primary coolant. The FHR DR is designed to be small, simple, and affordable.

Core design characteristics, fuel cycle performance, and safety analysis of the FHR DR preconcept have been evaluated. The FHR DR core design features a negative or negligible void coefficient throughout a reactor operating cycle. Both single-batch (cartridge) and multiple-batch fuel cycles can be demonstrated in the FHR DR. The single-batch cycle length of the FHR DR core is estimated at between 12-18 months, assuming the successful qualification of composite carbon

This manuscript has been authored by UT-Battelle, LLC under Contract No. DE-AC05-00OR22725 with the U.S. Department of Energy. The United States Government retains and the publisher, by accepting the article for publication, acknowledges that the United States Government retains a non-exclusive, paid-up, irrevocable, world-wide license to publish or reproduce the published form of this manuscript, or allow others to do so, for United States Government purposes. The Department of Energy will provide public access to these results of federally sponsored research in accordance with the DOE Public Access Plan (http://energy.gov/downloads/doe-public-access-plan ). 
(C/C) or silicon carbide $(\mathrm{SiC} / \mathrm{SiC})$ structural fuel block tie rod material. Fuel cycle performance of the FHR DR is similar to a high temperature gas-cooled reactor. Preliminary safety analysis of the FHR DR indicates that the reactor could be used to demonstrate the inherent safety characteristics of FHR designs.

Key Words: fluoride salt, FHRs, molten salt reactors, fuel cycle, safety analysis, advanced reactors.

\section{INTRODUCTION}

This paper is a companion paper to Qualls et al. (2017), which presents a high-level overview of a preconceptual design philosophy for a fluoride salt-cooled engineering demonstration reactor. This paper describes details of the reactor core design and preliminary safety analysis for that engineering demonstration reactor.

In 2015, the U.S. Congress authorized the U.S. Department of Energy Office of Nuclear Energy (DOE-NE) to initiate the Advanced Demonstration and Test Reactor (ADTR) study. The ADTR study evaluated advanced reactor technology options, capabilities, and requirements within the context of national needs and public policy to support innovation in nuclear energy. National laboratories, industry, and other relevant stakeholders of an advanced nuclear reactor conducted the ADTR study.

The fluoride high temperature salt-cooled reactor (FHR) engineering demonstration reactor (DR) is a preconceptual design for a small-scale demonstration reactor with the goal of increasing the technology readiness level (TRL) of the overall system (Qualls et al. 2016). The FHR DR was developed as a part of the broader ADTR study. The notional FHR DR concept, also known as a 
point design, described in this paper was developed for evaluation as part of the ADTR study. The potential missions of the demonstration reactor concepts in the ADTR study include: (1) process heat applications to reduce the carbon footprint of U.S. industry, (2) closing the nuclear fuel cycle and extending natural resource utilization, and (3) deploying a small scale engineering demonstration reactor with the goal of increasing the TRL of the overall system. Point designs were developed for several advanced reactor technology options (e.g. FHR, HTGR, SFR, and others) and considered against each potential mission. The FHR DR targets the third potential mission for an advanced engineering demonstration reactor. The methodology, approach, and findings of the ADTR study are outside the scope of this paper, which is focused on the technical details of the point design for the reactor core and safety analysis.

FHRs comprise a class of reactor concepts that use fluoride salts as low-pressure coolants to produce high-temperature heat with a high degree of inherent safety. In recent years, Oak Ridge National Laboratory (ORNL), the University of California, Berkeley (UCB), and the Massachusetts Institute of Technology (MIT) (among others) have developed salt-cooled FHR concepts.

The FHR DR will demonstrate many key features of FHRs including:

- tritium management, salt handling, and passive safety;

- active heat exchangers proposed for heat removal during maintenance outages for integral FHRs; and

- safety system operation to enable licensing and deployment of inherently safe commercial FHRs.

The FHR DR will demonstrate the inherent safety features of FHR designs, as Experimental Breeder Reactor II (EBR-II) demonstrated the potential for inherently safe sodium fast reactor 
designs with the shutdown heat removal tests (Planchon et al. 1986).

The FHR DR is designed to be an affordable, near-term system for demonstrating technology solutions that bridge remaining gaps to established technical viability. To meet that goal, lower risk technologies identified from previous experimental and design efforts are incorporated into the design. However, the flexibility of the facility also allows inclusion, demonstration, and qualification of other technologies being pursued for commercial development efforts.

Technology gaps for FHRs include demonstration of a fuel form for a commercial plant, including the ability to efficiently install and remove a core, in-core structural material performance, and inherent safety performance. Other technical uncertainties applicable to salt reactors pertain to salt procurement, chemistry control, and tritium management of lithium- and beryllium-containing salts. Operational uncertainties include demonstration of reliable pump and heat exchanger performance at temperatures of interest using relevant salt coolants. In addition, demonstration of control rod drive mechanisms will be an important aspect of the FHR DR.

The operating scheme for the FHR DR will resemble Shippingport, the historic light water reactor test bed that demonstrated three different core designs within the same vessel. Another relevant example of an engineering demonstration reactor is the EBR II. Similar flexibility in the FHR DR allows for testing of different fuel forms and cores as they become available. As part of the present work, the neutronics and thermal hydraulics of multiple fuel forms in an FHR DR core were evaluated and deemed acceptable. Based on an assessment of technology readiness, the baseline fuel form selected for the FHR DR was TRISO fuel compacts within a prismatic graphite block. This fuel form was previously demonstrated in high-temperature gas-cooled reactors.

\section{FHR DR Core Neutronic Design}


The FHR DR uses prismatic block-type fuel with integral fuel compacts and coolant channels as its base fuel form. The fuel is a typical high temperature gas-cooled reactor (HTGR) particle geometry with $15.5 \% \mathrm{UC}_{0.5} \mathrm{O}_{1.5}$ TRISO kernels with packing fractions of 0.35 within compacts. Selection of prismatic block-type fuel was motivated by the manufacturability of the prismatic fuel for HTGRs (Petti et al. 2009). The recent experience in the advanced gas reactor fuel irradiation program is another reason for this selection (Petti et al. 2010; Grover and Petti 2014a; Grover and Petti 2014b).

"FLiBe" $\left(2{ }^{7} \mathrm{LiF}-\mathrm{BeF}_{2}\right)$ is the primary loop coolant selected for the FHR DR. FLiBe features relatively attractive coolant properties, such as heat capacity and neutron moderation. This combination results in coolant temperature and void coefficients that are either negative or negligible (Williams et al. 2006, Žáková and Talamo 2008).

The prismatic block fuel type provides significant flexibility in enrichment zoning, fuel-coolant-moderator ratio, coolant distribution, and other core design parameters. The prismatic block fuel type was selected by MIT for their FHR test reactor concept (Forsberg et al. 2014). The cycle length of the FHR DR core is calculated to be 12-18 months with carbon composite (C/C) or silicon carbide composite ( $\mathrm{SiC} / \mathrm{SiC}$ ) structural tie rod components in the fuel blocks, with the following characteristics:

- prismatic block construction with an assembly pitch of $46 \mathrm{~cm}$,

- 180 fuel compacts and 109 coolant channels per fueled position,

- core height of $350 \mathrm{~cm}$ with a fueled height of $261 \mathrm{~cm}$,

- core diameter of $324 \mathrm{~cm}$ with a fueled diameter of $231 \mathrm{~cm}$, and

- $100 \mathrm{MW}$ thermal power. 
The completed core consists of 18 fueled hexagonal positions surrounded by 18 full-sized reflector and test positions, as shown in Fig. 1. Partial hexagonal positions near at core structure periphery are filled with graphite reflector to limit bypass flow between the core and the structure that restrains the core and forms the downcomer region within the vessel.

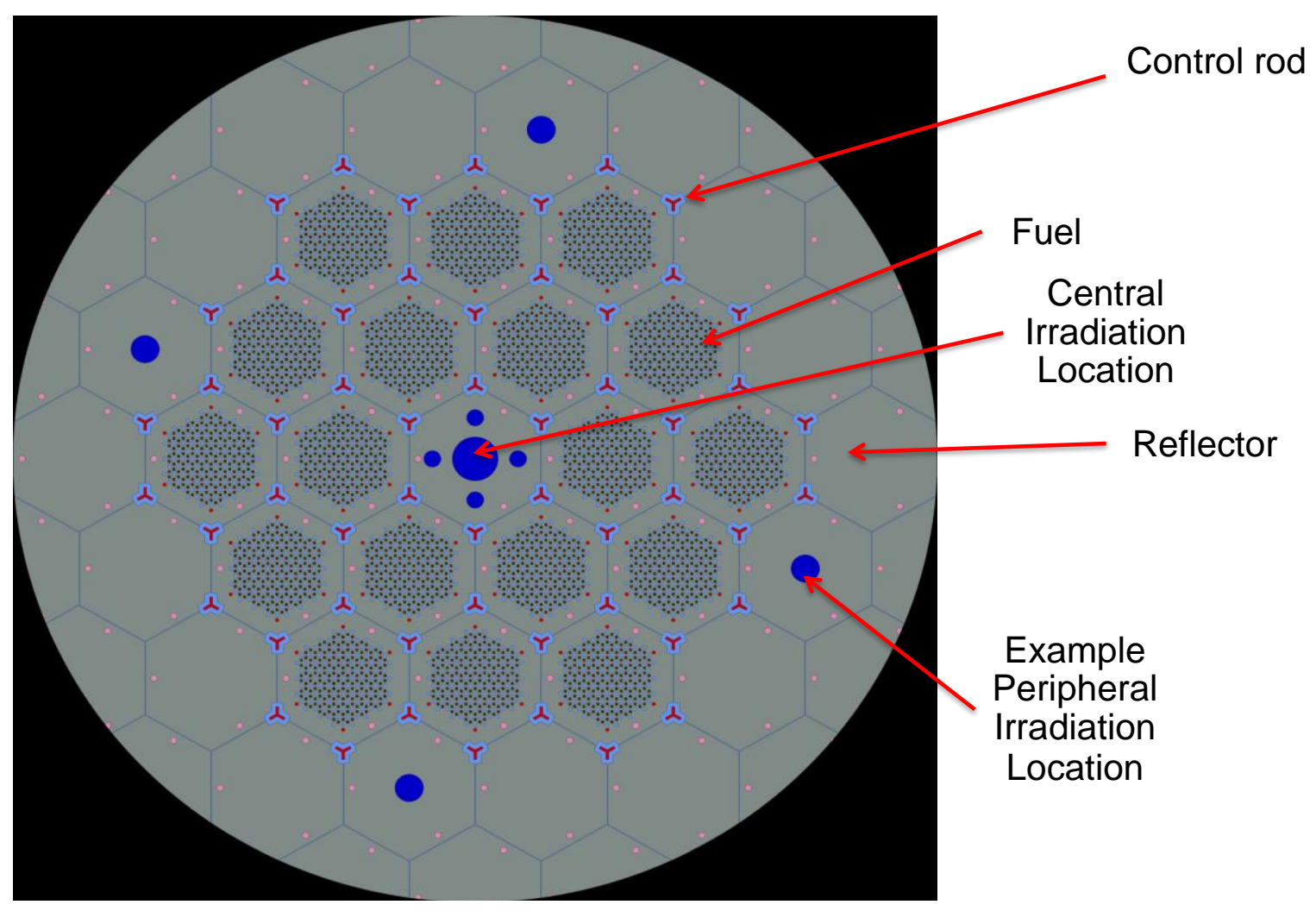

Fig. 1. Planar layout of the FHR DR neutronic model showing key features.

The baseline prismatic block fuel has the same hexagonal flat-to-flat distance as the reference plank fuel assembly for the Small Modular Advanced High Temperature Reactor (SmAHTR) (Greene et al. 2010) and the Advanced High Temperature Reactor (AHTR) (Holcomb et al. 2011) concepts. Therefore, the FHR DR core could later be exchanged for a similar plank-fueled core. Other proposed FHR fuel forms include uranium oxide, carbide, or nitride fuel pellets with an 
advanced cladding (silicon carbide or molybdenum-based), fuel particles in cylindrical fuel compacts within prismatic graphite blocks, fuel designs where particle fuel compacts are directly cooled by salt, fuel particles in graphite pebbles, and fuel particles in ceramic planks. AREVA NP Inc. (2007) previously investigated the potential for oxide pellet fuel forms in various fuel cycle missions within FHRs (e.g., burning of mixed-oxide fuel). Scoping neutronics calculations for the FHR DR indicate that these fuel forms may be feasible. Dysprosium oxide rods incorporated into prismatic fuel blocks may enable these configurations to maintain a negative void coefficient throughout the depletion cycle. The FHR DR has the capability to test any of these fuel forms prototypically (full height/power density) within the central unfueled hexagonal position. These capabilities include operation of lead test assemblies with instrumentation. The pebble fuel form would be tested within a fixed pebble bed in the central location, but pebble handling would be demonstrated in other facilities.

In addition to the central test location, fully instrumented irradiation locations in nonfuel blocks near the perimeter of the core allow for material specimen irradiations within instrumented and temperature controlled capsule assemblies.

The hexagonal core positions consist of an upper unfueled block, a fueled central block, and a lower unfueled block. The blocks are structurally connected using tie rods to form a single hexagonal stack that spans the height of the core. A lower core support plate attached to an internal support flange within the vessel positions each block assembly. Fuel block assemblies are outfitted with lifting and locating hardware to allow for placement on the lower core support plate and for positioning and stabilization within the core.

Each fueled assembly includes six burnable absorber channels located on the corners of the fuel 
region. These rods also reduce temperatures along the edges of the fueled regions, where the ratio of cooling to fuel channels is reduced. Absorber rods are composed of graphite with small weight fractions $(<2 \%)$ of natural $\mathrm{B}_{4} \mathrm{C}$ as a neutron absorber material similar to those used in HTGRs. The distribution of coolant and fuel channels within a hexagonal block is shown in Fig. 2. The unfueled moderator region on the outer edge of the block is the result of a scoping design study to determine the optimum fuel to moderator ratio. A similar design was employed in the MIT FHR test reactor concept (Forsberg 2014).

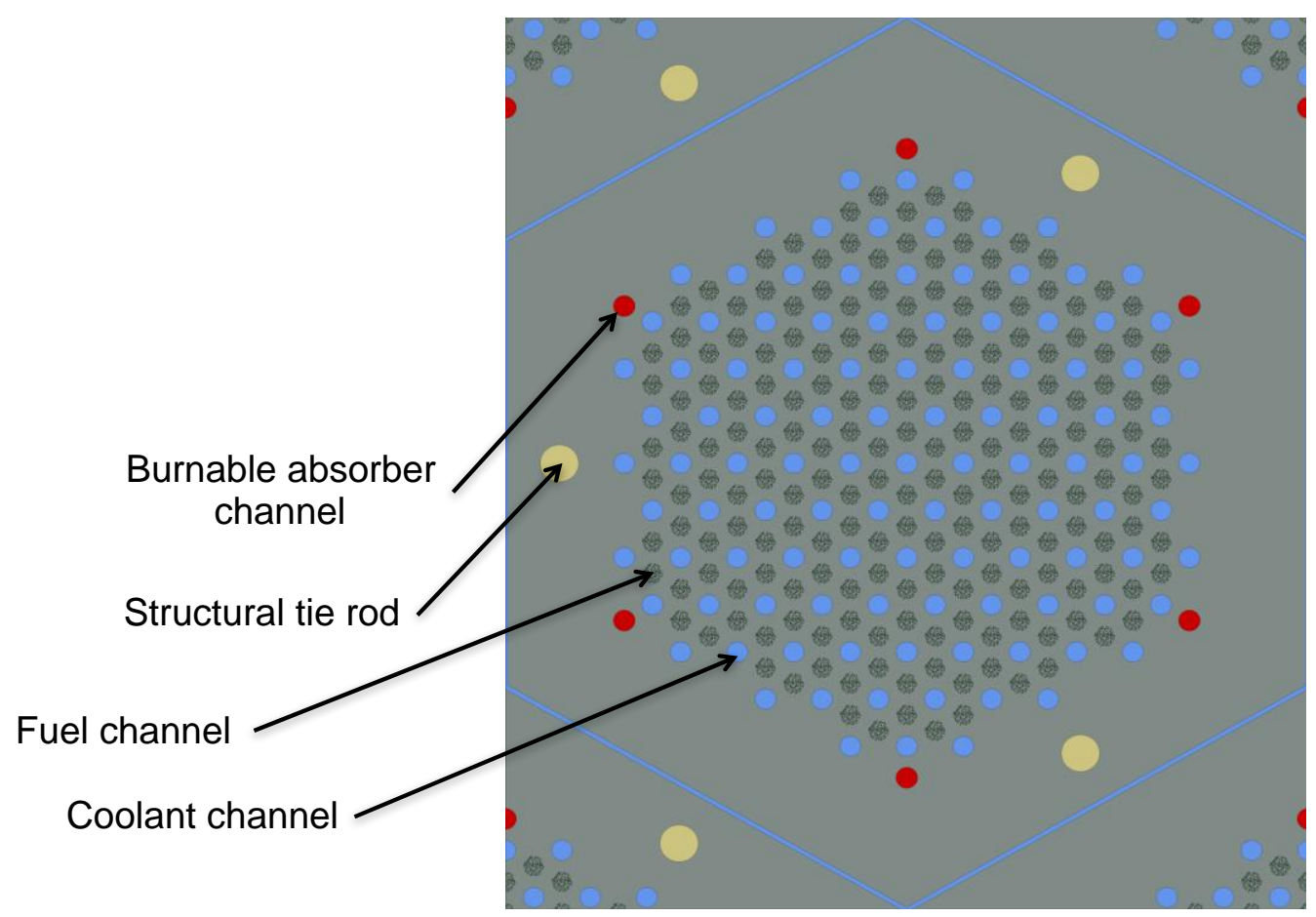

Fig. 2. Distribution of coolant and fueled channels within an FHR DR prismatic block. Coolant channels are blue, fuel compacts are dark green, burnable absorber compacts are red, and tie rods are yellow.

The baseline configuration of the FHR DR is a single-batch fuel management scheme, but the planned approach for the equilibrium cycle operation of the FHR DR may be a multiple batch 
scheme. In comparison to the single-batch case, the application of a multiple batch scheme decreases cycle length, but it increases fuel utilization through increased fuel residence time and discharge burn-up so that the operation may be more representative of commercial application.

Two reactor physics tools were selected for the design and analysis of the FHR DR. The primary design tool was Serpent, a continuous energy Monte Carlo reactor physics analysis tool (Leppänen, 2007). Serpent was selected for its capability to generate few-group parameters for neutron diffusion tools in arbitrary geometries, including those with double heterogeneity. Additionally, a modified version of the nodal core analysis tool PARCS (Downar et al., 2002) was used for some scoping analyses; PARCS is the US Nuclear Regulatory Commission (NRC) sponsored core simulator and is a state-of-the-art nodal diffusion code. PARCS is a three-dimensional simulator that solves the multi-group neutron diffusion equation in a variety of geometries. PARCS features built-in spatial kinetics capability for transient analysis and integrates a standalone thermal hydraulics module for single-phase coolant flow conditions with uranium oxide $\left(\mathrm{UO}_{2}\right)$ fuel. For this work, the PARCS thermal hydraulics module was modified to provide appropriate thermal hydraulic feedback for fluoride salts and fuel compacts in graphite. Additional details of this effort are presented in Section 3 of this paper.

The reactivity coefficients of the FHR DR are a key inherent safety feature of the reactor system. Example reactivity impacts of fuel temperature and coolant void are shown in Table 1 for one configuration at the beginning-of-cycle (BOC) condition. The differences are shown in percent millirho (pcm). The fuel temperature coefficient is strongly negative. The coolant void coefficient is negative or negligible throughout the cycle. The single-batch core $\mathrm{k}_{\mathrm{eff}}$ and the reactivity worth of complete voiding of the core are shown in Fig. 3 for an example configuration with $15.5 \%$ enriched 
uranium oxycarbide (UCO) kernels and a 0.35 packing fraction. This calculation was performed using the Serpent code. Note that not all reactivity coefficients are negative at all points in the cycle, but rather the net effect of the power coefficient is negative.

Table 1. Reactivity coefficients of an example FHR DR configuration at beginning-of-cycle

\begin{tabular}{lcccc}
\hline \multicolumn{1}{c}{ Configuration } & \multicolumn{4}{c}{ Coolant Configuration } \\
\cline { 2 - 5 } & \multicolumn{2}{c}{ Nominal (FLiBe: $1.95 \mathrm{~g} / \mathrm{cc})$} & \multicolumn{2}{c}{ Voided } \\
& $\mathrm{k}$ & $\Delta \mathrm{k}(\mathrm{pcm})$ & $\mathrm{k}$ & $\Delta \mathrm{k}(\mathrm{pcm})$ \\
Nominal $(1200 / 948 / 948 \mathrm{~K}$ & 1.02375 & - & 1.01732 & - \\
fuel/moderator/coolant) & 1.01723 & -652 & 1.00919 & -813 \\
Hot fuel $(1548 \mathrm{~K})$ & 1.03255 & 880 & 1.02583 & 851 \\
\hline Cold fuel $(900 \mathrm{~K})$ & & & & \\
\hline
\end{tabular}

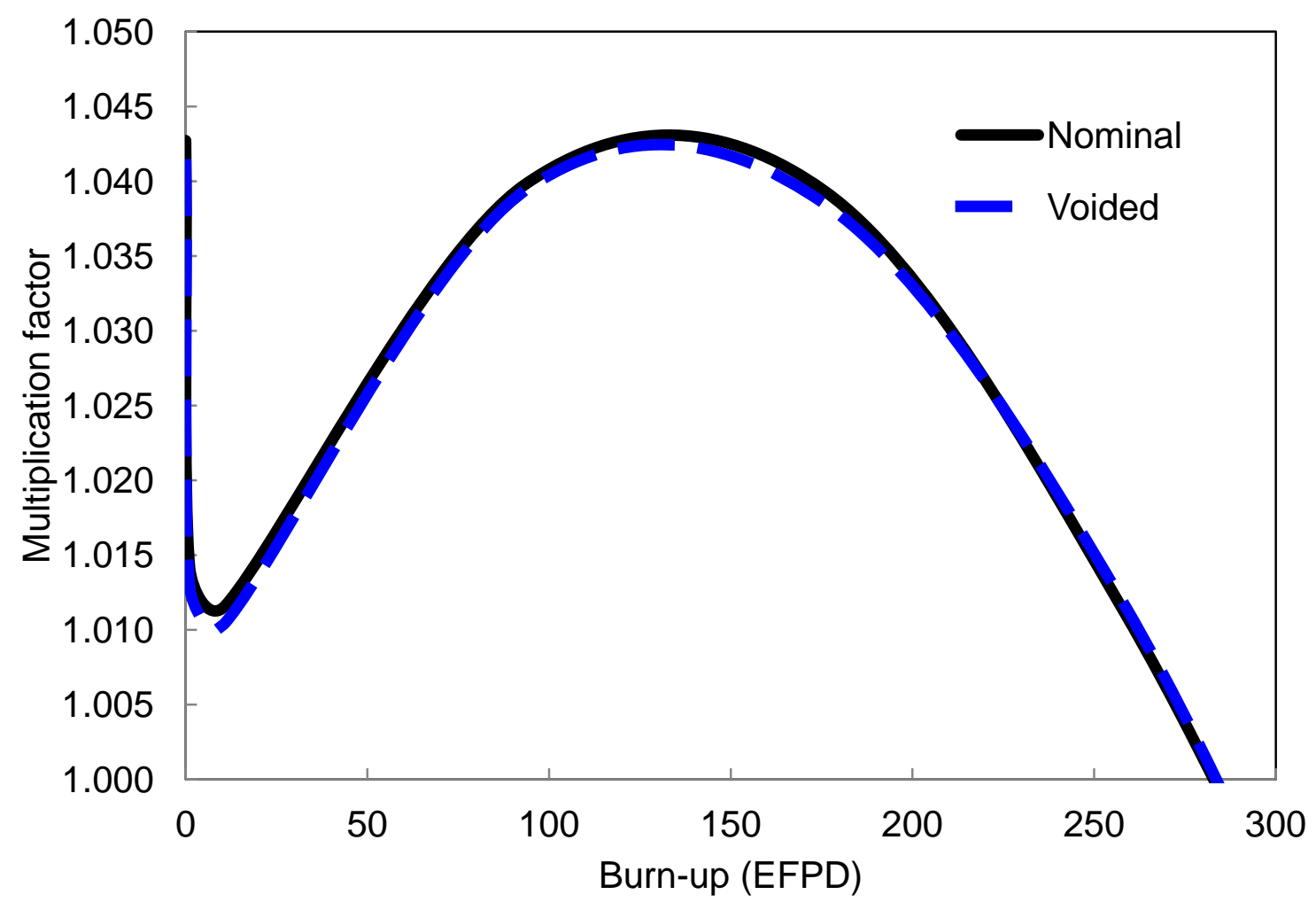

Fig. 3. Single-batch multiplication factor at nominal and void branch conditions during a 
depletion cycle; this is an example configuration with Alloy $800 \mathrm{H}$ structural tie rods.

The reference fuel cycle for the FHR DR is a once-through fuel cycle with LEU fuel (enrichment of $15.5 \%$ ) in UCO kernel TRISO particles, but the FHR DR is also capable of multibatch operation. The FHR DR is a thermal spectrum reactor, and the natural uranium resource utilization is less than $1 \%$ assuming a once-through cycle. In the context of the DOE-NE nuclear fuel cycle evaluation and screening (E\&S) (Wigeland et al. 2014), the relevant evaluation group (EG) is EG02. Interested readers are referred to Wigeland et al. (2014) for further details. The analysis example for EG02 was a graphite-moderated, He-cooled, TRISO-fueled high-temperature reactor, and the figures of merit used in that study are used here, highlighting key aspects of fuel cycle performance.

Table 2 shows fuel cycle performance parameters relevant for single-batch and three-batch fuel management schemes, with several different fuel packing fractions and example tie-rod materials. The base case with a nickel-based Alloy $800 \mathrm{H}$ tie rod material features natural resource utilization for a single-batch fuel cycle of $376 \mathrm{t} / \mathrm{GWe}-\mathrm{yr}$, corresponding to a 312-day single batch cycle length assuming a $90 \%$ capacity factor. Nickel and other constituents of Alloy $800 \mathrm{H}$ are parasitic neutron absorbers. Therefore, if $\mathrm{C} / \mathrm{C}$ or $\mathrm{SiC} / \mathrm{SiC}$ structural materials can be deployed the fuel cycle performance of the FHR DR could be improved. The best natural resource utilization for a single-batch fuel cycle is $320 \mathrm{t} / \mathrm{GWe}-\mathrm{yr}$, corresponding to a 549-day single batch cycle length assuming a 90\% capacity factor and an available and qualified ceramic composite tie rod material. The assumed electricity generation efficiency is $42 \%$, consistent with the E\&S study, although it is possible that the FHR DR would be capable of generating electricity at higher thermal efficiencies 
because of its high outlet temperature.

Table 2. Example fuel cycle performance parameters of the FHR DR

\begin{tabular}{|c|c|c|c|c|c|}
\hline \multirow{2}{*}{$\begin{array}{l}\text { Parameter } \\
\text { Enrichment (\%) }\end{array}$} & & \multicolumn{4}{|l|}{ Value } \\
\hline & & & 15 & & \\
\hline \multicolumn{2}{|l|}{ Capacity factor } & \multicolumn{4}{|c|}{0.9} \\
\hline \multicolumn{2}{|l|}{ Electrical efficiency } & \multicolumn{4}{|c|}{0.42} \\
\hline Packing fraction & - & 0.35 & 0.35 & 0.3 & 0.25 \\
\hline \multirow{2}{*}{ Tie rod material } & & \multirow{2}{*}{ Alloy $800 \mathrm{H}$} & $\mathrm{C} / \mathrm{C}$ or & $\mathrm{C} / \mathrm{C}$ or & $\mathrm{C} / \mathrm{C}$ or \\
\hline & & & $\mathrm{SiC} / \mathrm{SiC}$ & $\mathrm{SiC} / \mathrm{SiC}$ & $\mathrm{SiC} / \mathrm{SiC}$ \\
\hline Burnable poison? & & Yes & No & No & No \\
\hline \multirow{2}{*}{ Burnup (GWd/t) } & 1-batch & 51.1 & 90 & 76.6 & 56.8 \\
\hline & 3-batch & 76.6 & 135 & 115 & 85.2 \\
\hline \multirow{2}{*}{$\begin{array}{l}\text { Fuel residence time (full power } \\
\text { days) }\end{array}$} & 1-batch & 312 & 549 & 405 & 246 \\
\hline & 3-batch & 468 & 823 & 608 & 370 \\
\hline \multirow{2}{*}{ Charge mass flow (t/GWe-yr) } & 1-batch & 17 & 9.7 & 11.3 & 15.3 \\
\hline & 3-batch & 11.4 & 6.4 & 7.6 & 10.2 \\
\hline \multirow{2}{*}{$\begin{array}{l}\text { Natural resource required } \\
(\mathrm{t} / \mathrm{GWe}-\mathrm{yr})\end{array}$} & 1-batch & 563 & 320 & 375 & 507 \\
\hline & 3-batch & 376 & 213 & 250 & 338 \\
\hline
\end{tabular}

The fuel cycle performance parameters in Table 2 were calculated using the methodology from the E\&S (Wigeland et al. 2014):

- Fuel residence time: $\quad F R T(y r)=\frac{B U\left(\frac{M W d}{t}\right)}{\operatorname{SPD}\left(\frac{M W}{t}\right) \times 365\left(\frac{d}{y r}\right) \times \eta}$,

- Cycle length: $\quad C(y r)=F R T(y r) / n_{\text {batch }}$,

The charge fuel mass and natural resources required per unit electricity generation were obtained from: 
- Charge fuel mass: $\quad \bar{M}_{\text {charge }}^{\text {fuel }}\left(\frac{t}{G W e \times y r}\right)=\frac{P_{\text {thermal }}(M W)}{B U\left(\frac{M W d}{t}\right) \times P_{\text {electric }}(M W)} \times \frac{365 d}{1 y r}$, and

- Required natural uranium resource: $\quad \bar{M}_{N U}\left(\frac{t}{G W e \times y r}\right)=\bar{M}_{\text {charge }}^{\text {fuel }}\left(\frac{t}{G W e \times y r}\right) \times \frac{\left(e n r_{L E U}-e n r_{\text {tails }}\right)}{\left(e n r_{N U}-e n r_{t a i l s}\right)}$.

where

$\mathrm{P}_{\text {thermal }} \quad=$ reactor thermal power $[\mathrm{MW}]$

$\mathrm{SPD}=$ specific power density $[\mathrm{MW} / \mathrm{t}]$

$\mathrm{n}_{\text {batch }}=$ number of fuel batches in the core,

$\mathrm{BU}=$ fuel average discharge burnup $[\mathrm{MWd} / \mathrm{t}]$,

$\eta \quad=$ reactor capacity factor, and

$e n r=15.5 \%$ for LEU, $0.25 \%$ for tails, and $0.711 \%$ for natural uranium $(\mathrm{NU})$.

The FHR DR could also demonstrate a portion of an advanced fuel cycle. One option is the use of uranium and thorium feed fuel in TRISO form (UTh feed). This would use both LEU fuel and fertile thorium fuel, corresponding to EG05 in the E\&S (Wigeland et al. 2014). Another potential example of an advanced fuel cycle application of the FHR DR is the use of deep-burn TRISO fuel with plutonium or transuranic recycle. Thus, the proposed fuel materials (in TRISO particle form) that could be demonstrated in the FHR DR include LEU fuel, UTh fuel, plutonium fuel, and transuranic fuel.

The graphite-moderated baseline configuration of the FHR DR is designed to provide peak thermal fluxes in the central irradiation thimble. This thimble will be used to qualify desired fuel 
forms in commercially relevant FHR irradiation conditions and will be instrumented to enable validation of high-fidelity simulation tools. The radial thermal neutron flux distribution in the FHR DR is shown in Fig. 4 and the radial fast neutron flux distribution in Fig. 5. These calculations come from the Serpent code. The peak thermal flux (less than $0.625 \mathrm{eV}$ ) in the central irradiation thimble is $2.5 \times 10^{14} \mathrm{n} / \mathrm{cm}^{2}-\mathrm{s}$, and the peak fast flux (greater than $0.1 \mathrm{MeV}$ ) is $1.25 \times 10^{14} \mathrm{n} / \mathrm{cm}^{2}$-s and is located in the fuel positions surrounding the central irradiation thimble. The peak fast neutron fluence $(>0.18 \mathrm{MeV})$ expected in the TRISO fuel kernels for the base case is $3.5 \times 10^{21} \mathrm{n} / \mathrm{cm}^{2}$. The average neutron flux spectrum in the FHR DR core is shown in Fig. 6.
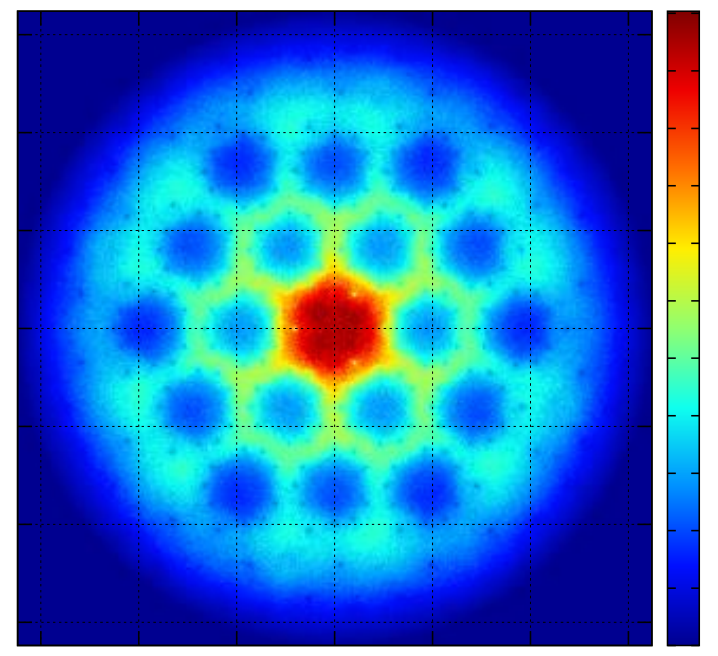

Fig. 4. FHR DR radial thermal flux distribution. 


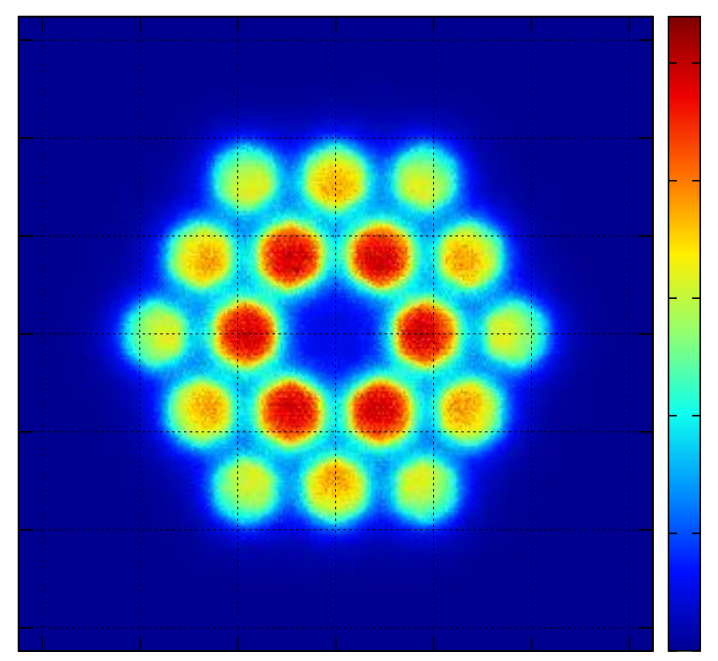

$x$

Fig. 5. FHR DR radial fast flux distribution. 


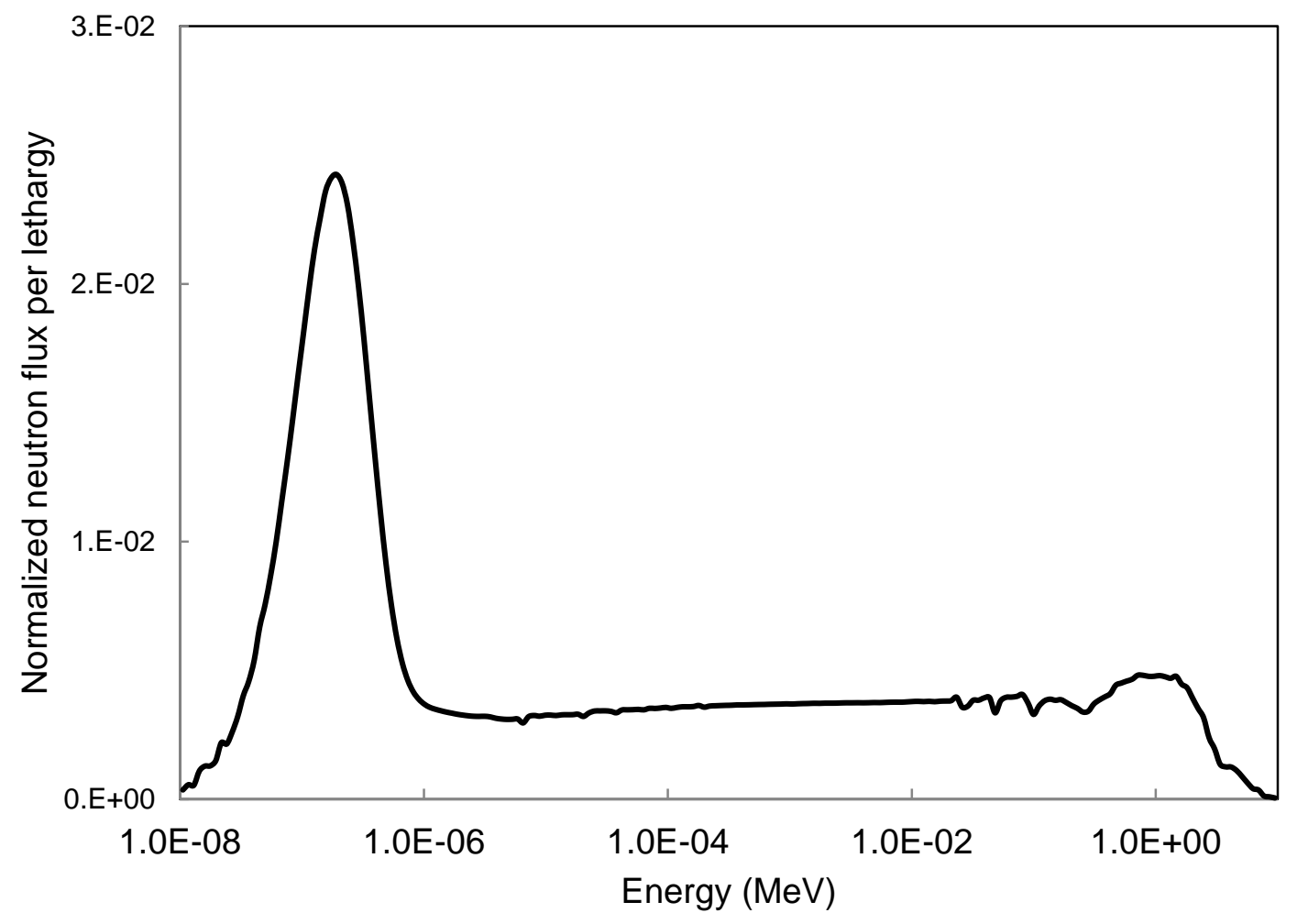

Fig. 6. FHR DR neutron flux spectrum.

The FHR DR core is designed to be reconfigurable, with more than three possible permutations. The base configuration consists of two rings of fuel assemblies with a central irradiation zone. There are nine irradiation thimbles spanning the axial height of the core, which is $3.5 \mathrm{~m}$. These include four irradiation thimbles on the periphery of the core, four small irradiation thimbles in the central thimble, and the large central test position. In another core configuration, such as a configuration where the central test thimble is replaced with a fuel block, the irradiation volume available would be different. The reflector blocks can also be replaced with blocks containing irradiation thimbles. The available irradiation volumes in the FHR DR base configuration are detailed in Table 3 . These volumes and thimble configurations are preliminary but indicative, and 
they assume that $40 \%$ of the thimble radii is available for irradiation volume. The total available irradiation volume is $30 \mathrm{~L}$, and $3 \mathrm{~m}$ of axial height is available for irradiation.

Table 3. Irradiation volumes in the FHR DR baseline configuration

\begin{tabular}{llll}
\hline Irradiation volume & $\begin{array}{l}\text { Number of } \\
\text { locations }\end{array}$ & $\begin{array}{l}\text { Available } \\
\text { axial height } \\
(\mathbf{m})\end{array}$ & $\begin{array}{l}\text { Available } \\
\text { volume (L) }\end{array}$ \\
\hline Large central thimble & 1 & 3 & 10 \\
Small central thimbles & 4 & 3 & 5 \\
Peripheral thimbles & 4 & 3 & 15 \\
\hline
\end{tabular}

The current configuration is not a final design, but it is an acceptable baseline core arrangement for further FHR DR study and development. Other core arrangements are possible, and flexibility in core configuration is a key feature of the FHR DR concept. In a single-batch fuel management scheme the operating cycle is 12 - 18 months, assuming availability of a qualified ceramic tie rod material. An allowed 50-day outage for refueling and maintenance results in an expected availability of approximately 85-90\%. The current core configuration assumes nickel-plated Alloy $800 \mathrm{H}$ tie rods for fuel element structural materials. Alloy $800 \mathrm{H}$ is a near-term option with excellent high-temperature strength, but it has relatively high parasitic neutron absorption. Key reactor design parameters of the current FHR DR configuration are shown in Table 4.

Table 4. Key reactor parameters

\begin{tabular}{|c|c|c|}
\hline Parameter & Unit & Value \\
\hline Reactor thermal power & MWt & 100 \\
\hline $\begin{array}{l}\text { Targeted net thermal efficiency of derived } \\
\text { commercial application }\end{array}$ & $\%$ & 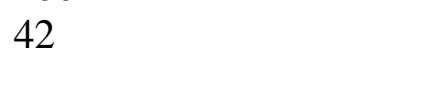 \\
\hline Primary coolant & & $2^{7} \mathrm{LiF}_{-} \mathrm{BeF}_{2}$ \\
\hline Lithium-7 enrichment level & $\%$ & 99.995 \\
\hline Fuel type & & $\mathrm{UC}_{0.5} \mathrm{O}_{1.5}$ coated particle \\
\hline
\end{tabular}




\begin{tabular}{|c|c|c|}
\hline Parameter & Unit & Value \\
\hline Fuel packing & $\%$ & $30-40$ \\
\hline${ }^{235} \mathrm{U}$ enrichment level & $\%$ & 15.5 (baseline) \\
\hline Reflector material & & Graphite \\
\hline Reactor vessel internals material & & Alloy $800 \mathrm{H}$ lined w/alloy $\mathrm{N}$ \\
\hline Core structural material & & $\mathrm{C} / \mathrm{C}$ composites \\
\hline Control blade material & & $\begin{array}{l}\text { Molybdenum Hafnium Carbide } \\
\text { alloy }\end{array}$ \\
\hline Primary coolant flow rate & $\mathrm{kg} / \mathrm{s}$ & $\sim 1000$ \\
\hline Number of primary loops & & 2 \\
\hline Typical refueling interval & Months & $\sim 12-18$ \\
\hline Fuel format & & $\begin{array}{l}\text { Prismatic block with coolant } \\
\text { channels and fuel compacts }\end{array}$ \\
\hline Mixed mean core outlet temperature & ${ }^{\circ} \mathrm{C}$ & 701 \\
\hline Core inlet temperature & ${ }^{\circ} \mathrm{C}$ & 660 \\
\hline Number of fuel assemblies & & $\begin{array}{l}18 \text { fueled (baseline core, } \\
\text { configuration is flexible) }\end{array}$ \\
\hline Core fueled height & $\mathrm{m}$ & 2.61 \\
\hline Core pressure drop for normal operation & atm & 0.6 \\
\hline
\end{tabular}

\section{FHR DR thermal-hydraulic design and core analysis}

Several tools were used to perform thermal-hydraulic design calculations: COMSOL (COMSOL 2015) and RELAP5-3D (RELAP5-3D Code Development Team 2014). COMSOL was used to calculate assembly-level fuel and graphite temperatures, and the RELAP5-3D code was used to perform overall system calculations. In addition, the U.S. Nuclear Regulatory Commission (NRC) tool TRACE (U.S. NRC 2012) was used to confirm the RELAP5-3D predictions of thermal feedback during transients. The PARCS regulatory-grade core simulator was used to perform analyses of steady-state neutronics and thermal hydraulics. The system layout for the FHR-DR is described in some detail in Qualls et al. (2016, 2017).

Fig. 7 shows a typical assembly as modeled by COMSOL. Average values of heat generation in the fuel and of coolant temperature were employed. Heat generation in the graphite was assumed to 
be nil, which is a conservative assumption that predicts higher fuel temperatures. Some heat generation will occur in the graphite, which will increase the graphite temperatures and decrease the predicted fuel temperatures. Conservative values for a steady-state analysis are assumed for the thermal conductivity of the fuel compacts and the graphite as well as the heat transfer coefficients to the coolant.

$$
\text { Surface: Temperature (degC) }
$$

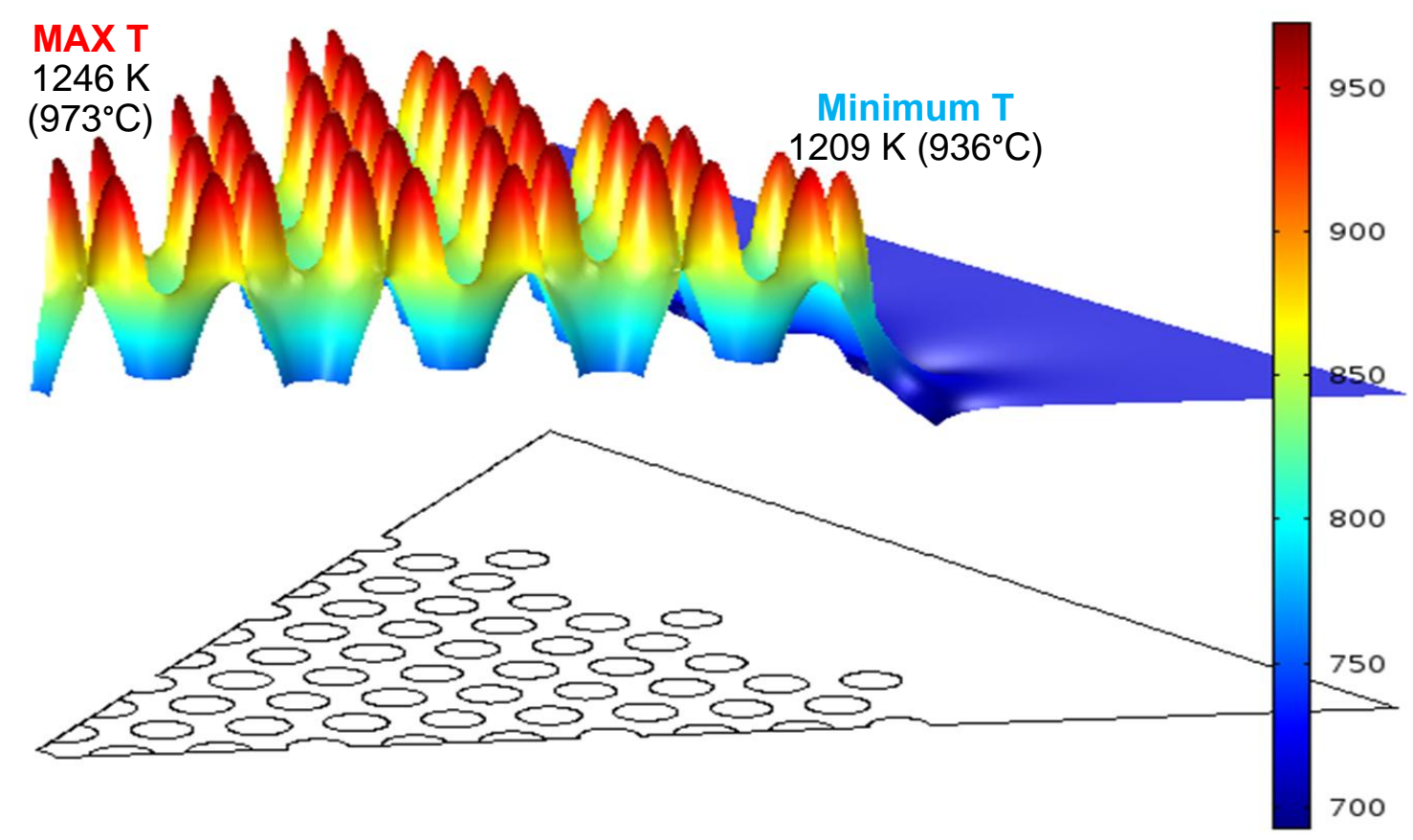

Fig. 7. Example COMSOL thermal calculation for the FHR DR assembly.

The RELAP5-3D model of the system is shown in Fig. 8 and includes two primary loops with two heat exchangers, two primary pumps, and the two secondary loops. The core nodalization includes four channels: one for the central hexagonal block, two channels for the two fueled core rings (with 6 and 12 assemblies in each ring, respectively), and an additional channel for the 
peripheral reflector graphite blocks. The channels are also subdivided into ten axial nodes with eight nodes facing the active core. The fuel is modeled as cylindrical structures surrounded by graphite and by the coolant channels. The axial power distribution was derived from neutronic analyses and assumes an axial peaking factor of 1.28 .

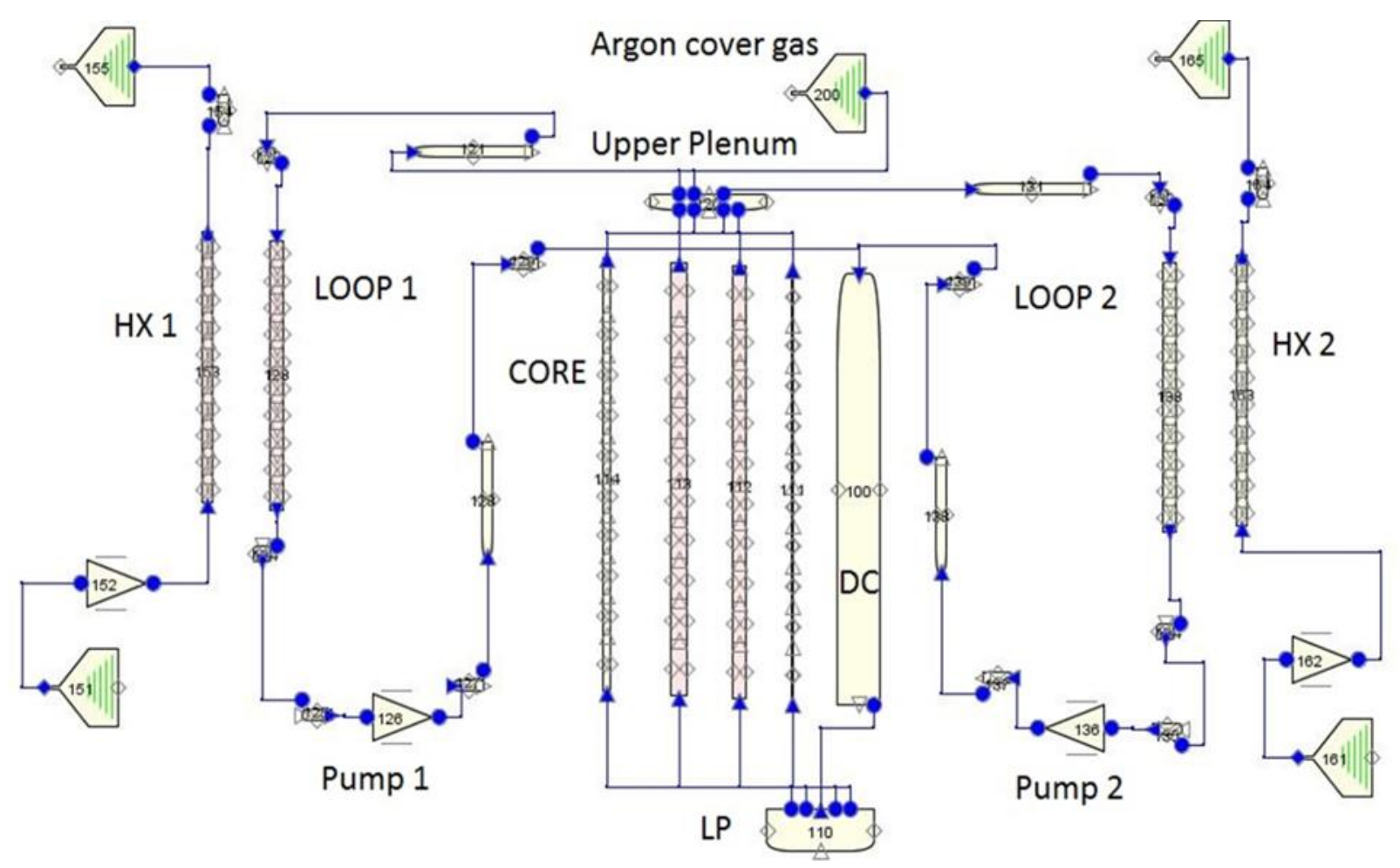

Fig. 8. RELAP5-3D model of the FHR DR.

Additional structures are employed to model the remaining graphite in the fuel assemblies and the graphite of the reflector blocks. The two heat exchangers and the three direct reactor auxiliary cooling system (DRACS) heat exchangers are also modeled. The pipes employed in the system loops have an inner diameter of $0.305 \mathrm{~m}$ to keep the coolant velocity under $4 \mathrm{~m} / \mathrm{s}$, which minimizes pumping power. Calculations have been completed for steady state conditions at full power and for a loss of forced flow (LOFF) with reactor scram. During normal operation at full power, the 
DRACS are inactive, and a forced convection flow of $1,048 \mathrm{~kg} / \mathrm{s}(524 \mathrm{~kg} / \mathrm{s} / \mathrm{pump})$ circulates through the whole core. The coolant $\Delta \mathrm{T}$ through the core is $40^{\circ} \mathrm{C}$. Each secondary loop has a flow of $530 \mathrm{~kg} / \mathrm{s}$ of FLiNaK and a $\Delta \mathrm{T}$ of $50^{\circ} \mathrm{C}$. Further details of the thermal hydraulics models are presented in Carbajo et al. (2016).

Neutronics calculations were performed using both Monte Carlo transport (Serpent) and nodal diffusion (PARCS). The nodal diffusion calculations were performed with thermal and hydraulic feedback. For the nodal diffusion calculations, a 4-group structure developed for the AHTR was used (Gentry, et al. 2016). Although developed for a different concept (plank fuel), this 4-group structure provides reasonable agreement between transport and diffusion solutions at a low computational cost. The nodal diffusion calculations were performed using PARCS. The difference between the Serpent Monte Carlo transport solution and the 4-group PARCS diffusion solution is shown in Fig. 9 as a function of burn-up for the AHTR assembly configuration described in Gentry, et al. (2016) and also for the prismatic fuel configuration of the FHR DR preconceptual design. For these examples, the diffusion solution is typically within $100 \mathrm{pcm}$ of the transport solution.

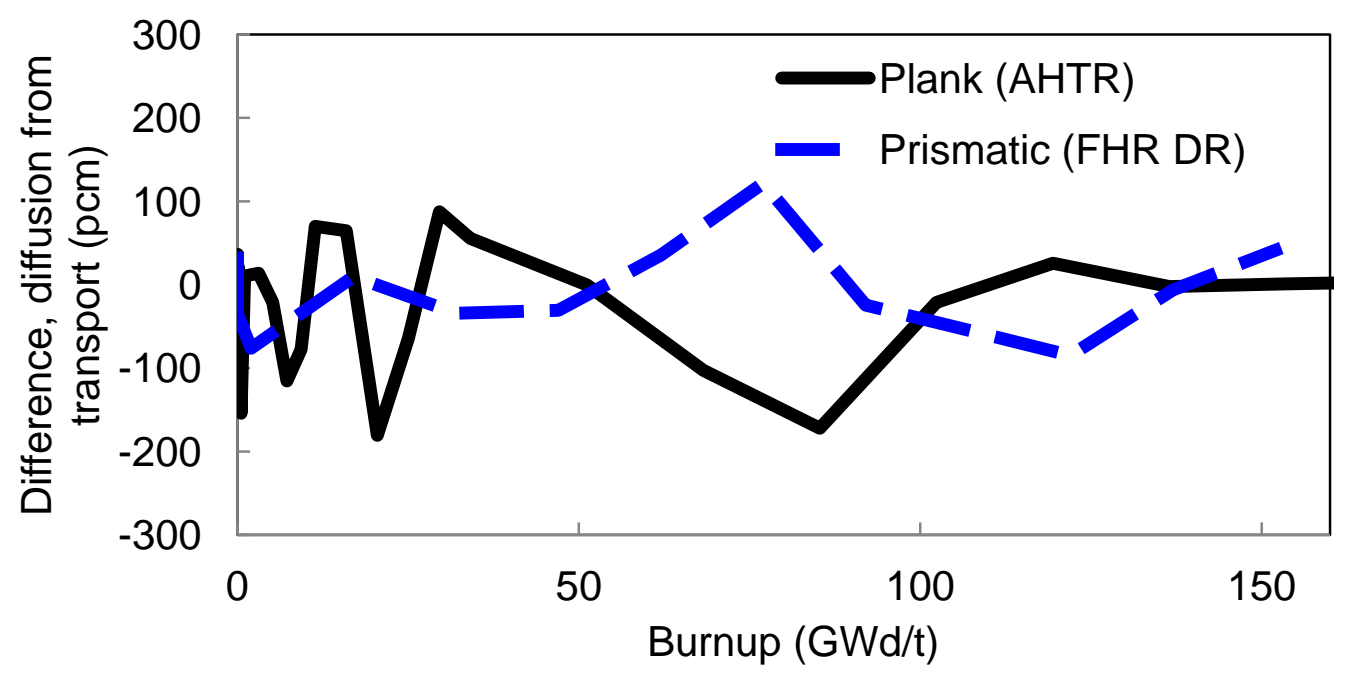


Fig. 9. Differences between PARCS neutron diffusion and transport solutions for the AHTR

(Gentry et al. 2016) and FHR DR.

Thermal properties for graphite, fuel compacts, and salt were integrated into the PARCS core simulator. The simplified approach for modeling the thermal and hydraulic feedback, intended only for scoping evaluation of the design and not for final, best-estimate analysis, is shown in Fig. 10. The simplification entails modeling the detail of the core geometry as a single fuel assembly, with the total flow area and fuel volume of the entire core, and with fuel thermal conductivity adjusted to provide the fuel temperatures determined through the thermal hydraulics analyses previously described. Although the simplified approach is sufficient for the present purposes, the development of best-estimate core analysis tools remains a significant need for salt cooled reactor systems.
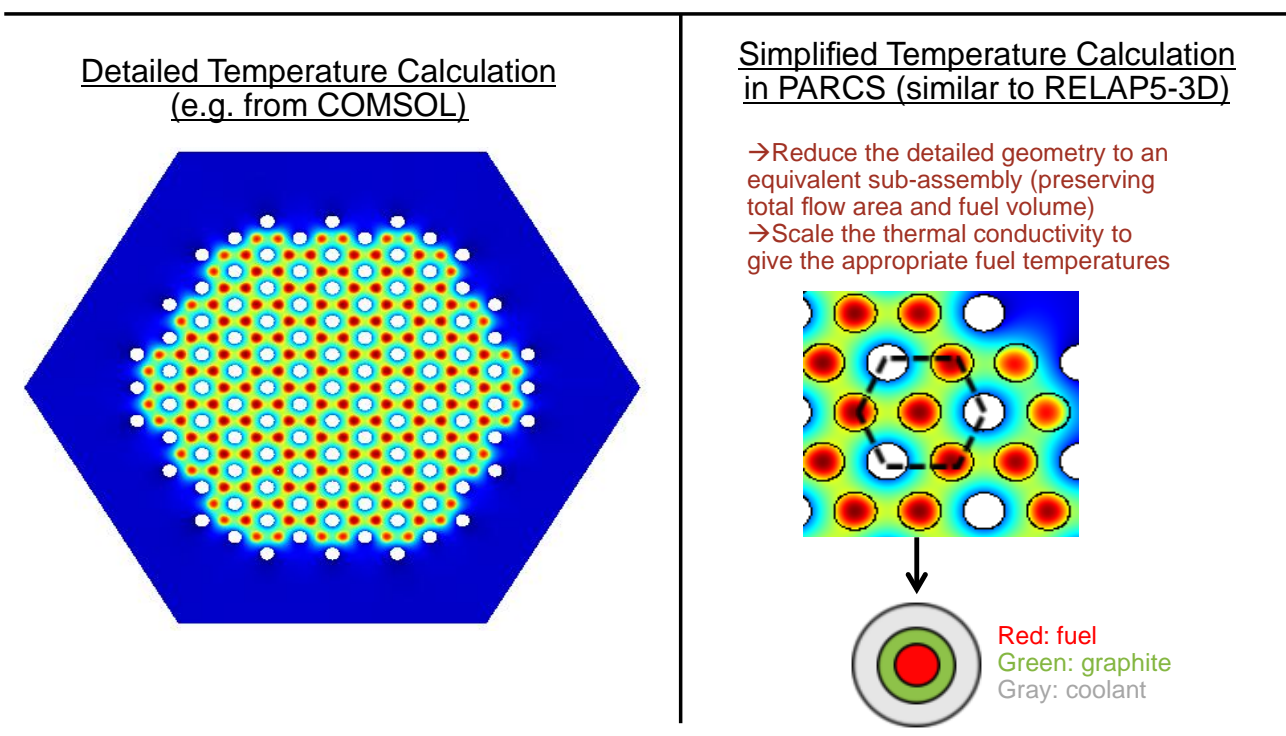

Fig. 10. Simplified thermal and hydraulic modeling approach used in the PARCS core simulator scoping calculations. 
Code-to-code comparison of the thermal performance of the FHR DR was used to enhance confidence in the PARCS results. Comparisons were conducted using COMSOL, RELAP5-3D, TRACE, and the FHR version of the NESTLE nodal core simulator described in Gentry et al. (2016) and Petrovic and Maldonado (2016). An example comparison is shown in Fig. 11 for AHTR geometry. The comparison between PARCS and NESTLE with thermal and hydraulic feedback will be described in a future publication. For the present purpose, it is sufficient to note that the PARCS model provides reasonable agreement with the NESTLE model.
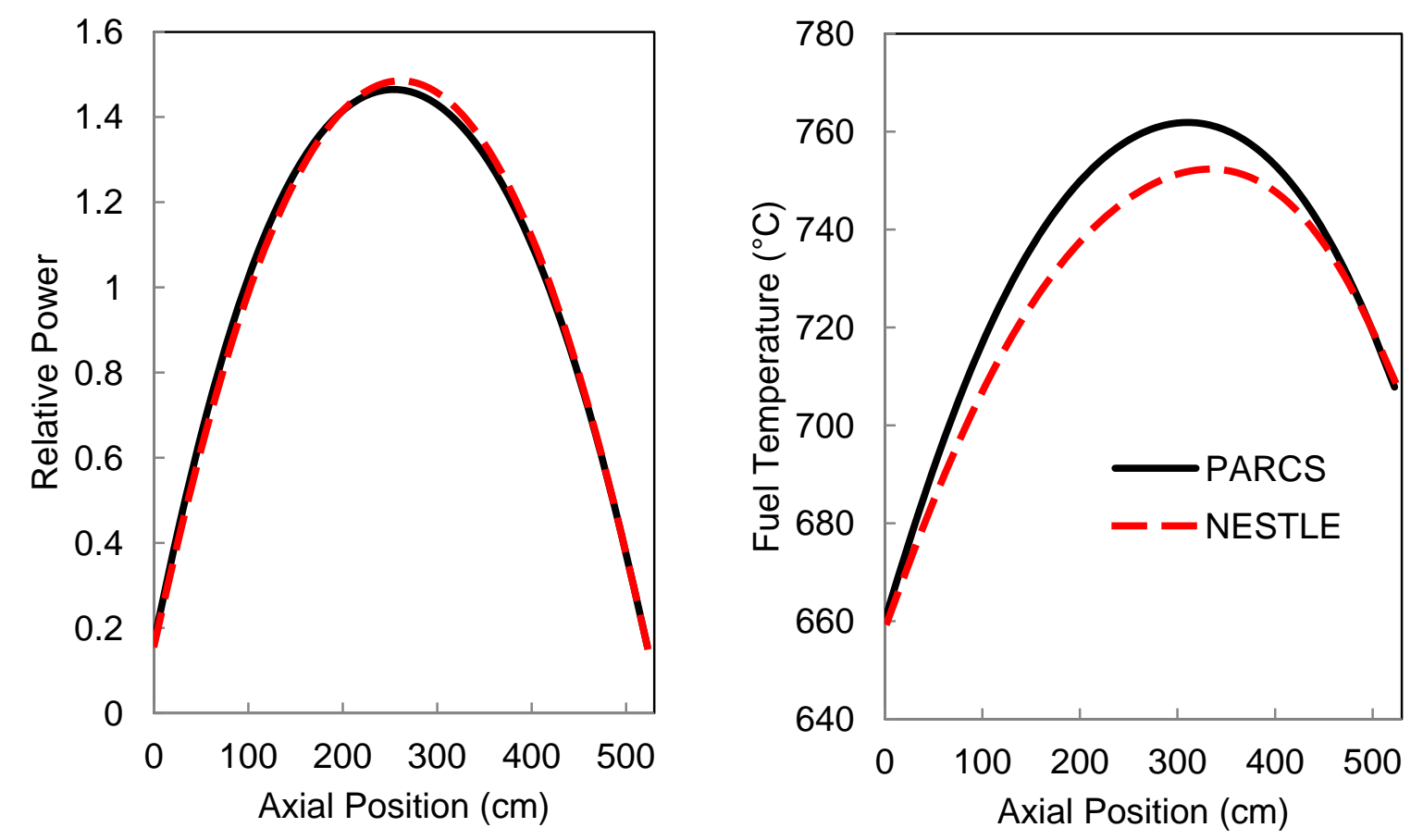

Fig. 11. Example comparison of relative power and fuel temperature for a simple FHR problem in the PARCS and NESTLE nodal core analysis tools. (Note that the legend is the same for both plots). 
The PARCS calculated radial power distribution in the FHR DR at BOC and end-of-cycle (EOC) conditions is shown in Fig. 12. The predicted assembly average fuel temperatures at BOC and EOC are shown in Fig. 13. The axial and radial peaking factors are shown in Fig. 14 throughout an example burn-up cycle. The radially averaged axial power distribution is shown in Fig. 15. The radially averaged axial fuel temperature distribution is shown in Fig. 16 and coolant temperature distribution in Fig. 17. These scoping core analysis results and parameters are considered reasonable per acceptability of the preliminary safety analysis in Section 4.

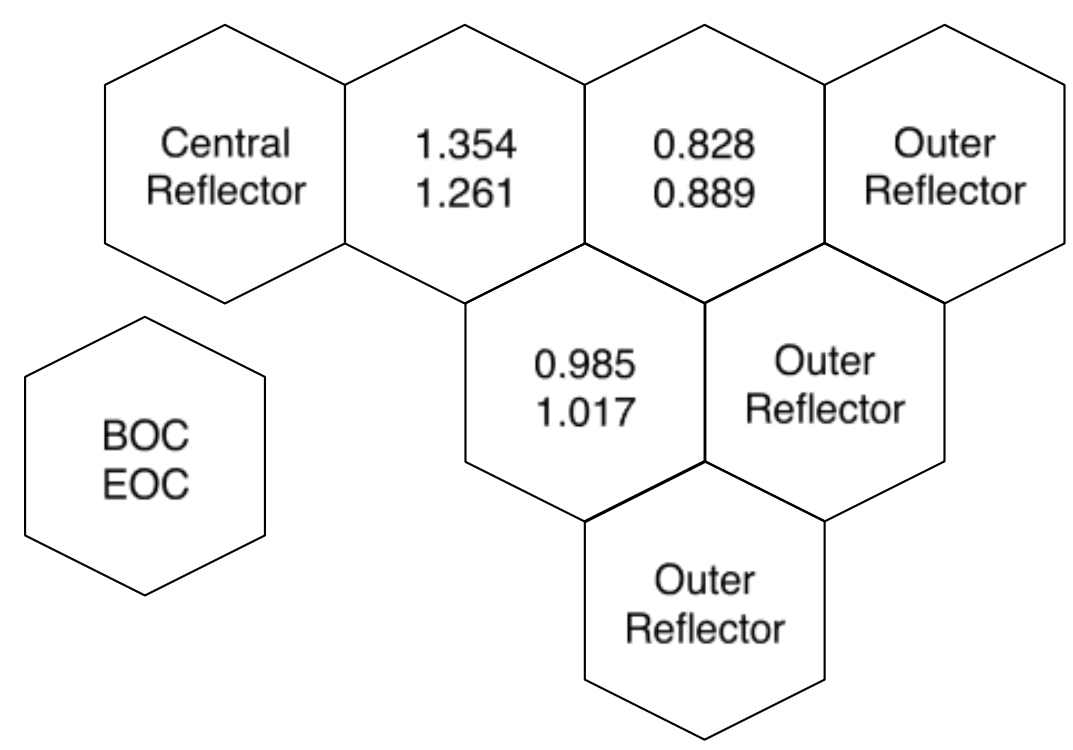

Fig. 12. Predicted relative power distribution in the FHR DR (the reactor core is $1 / 6$-th symmetric in these scoping calculations). 


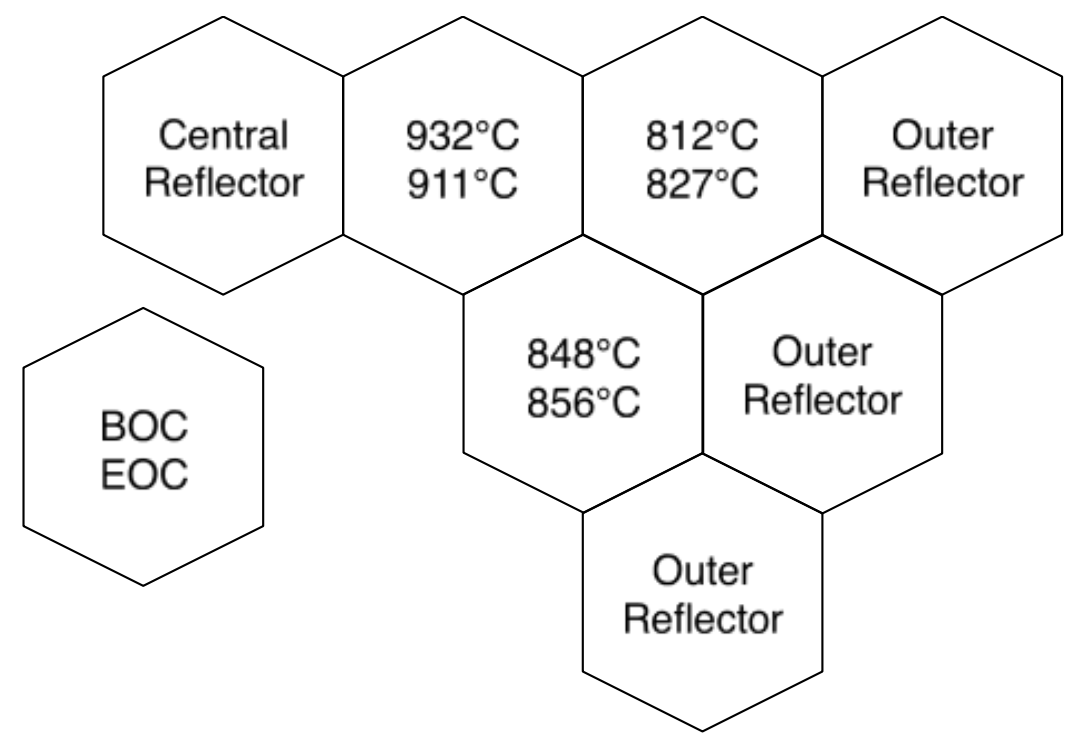

Fig. 13. Predicted assembly average fuel temperatures in the FHR DR (the reactor core is 1/6-th symmetric in these scoping calculations).

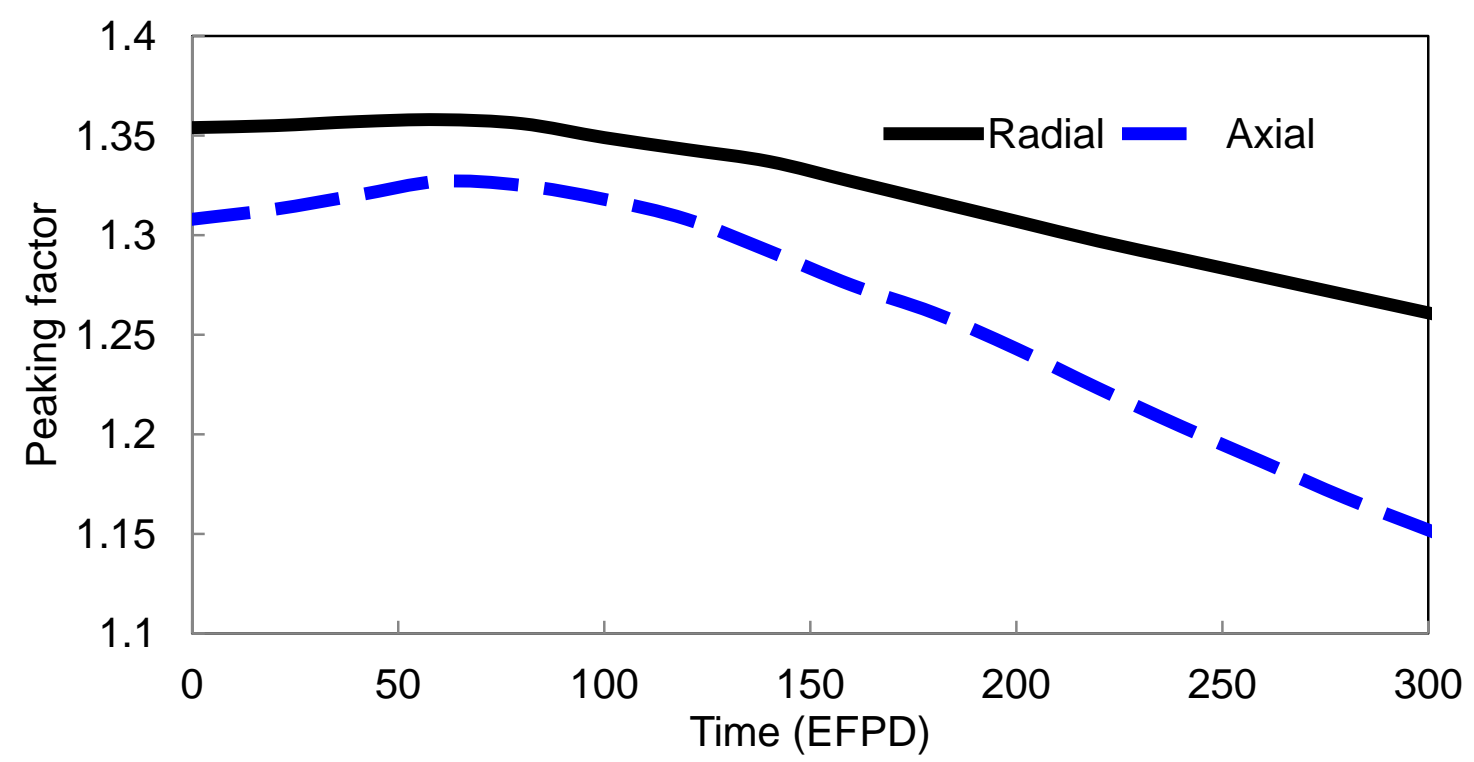

Fig. 14. Axial and radial peaking factors in the FHR DR predicted throughout a burn-up cycle. 


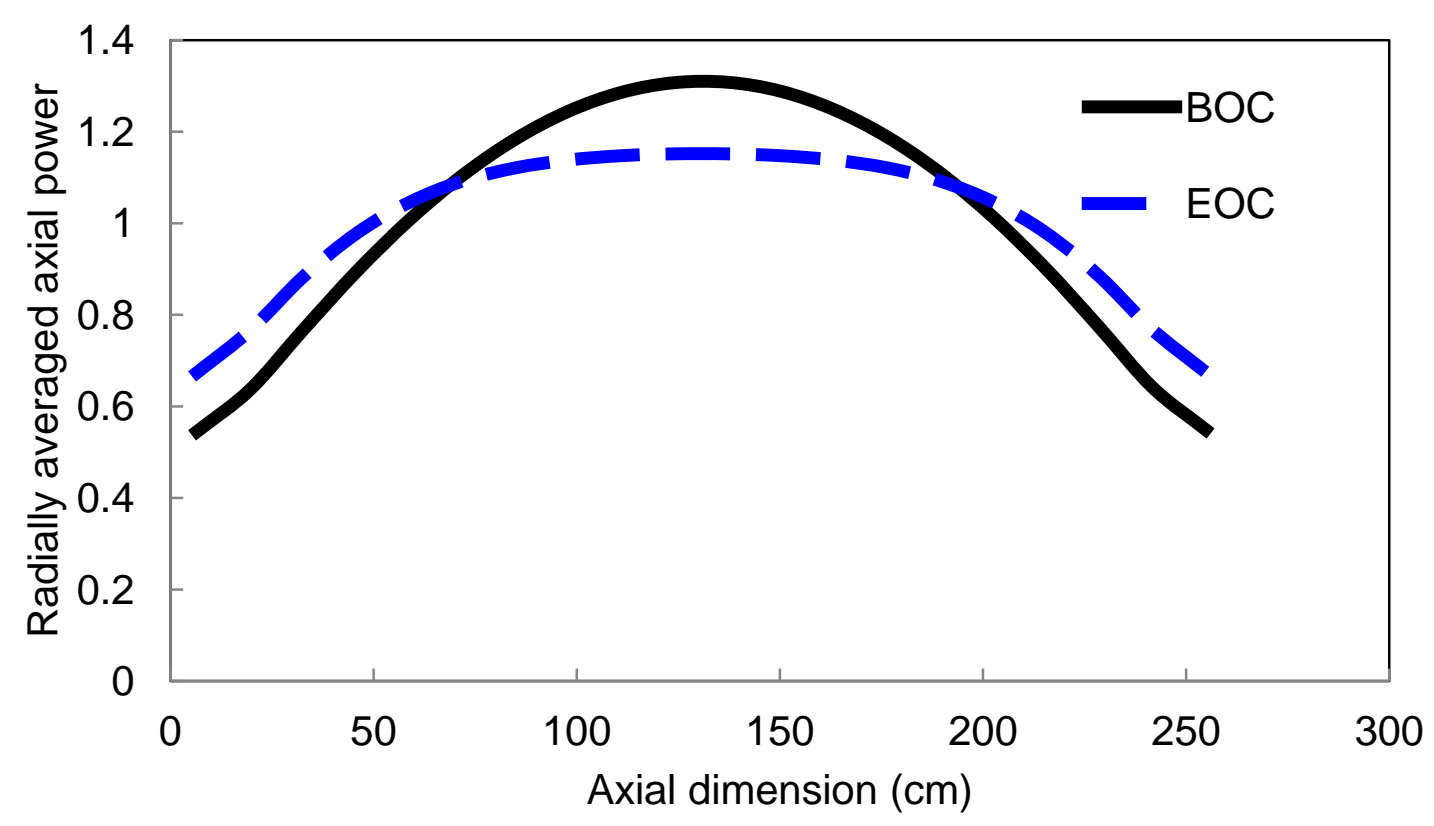

Fig. 15. Radially averaged axial power distribution in the FHR DR at BOC and EOC.

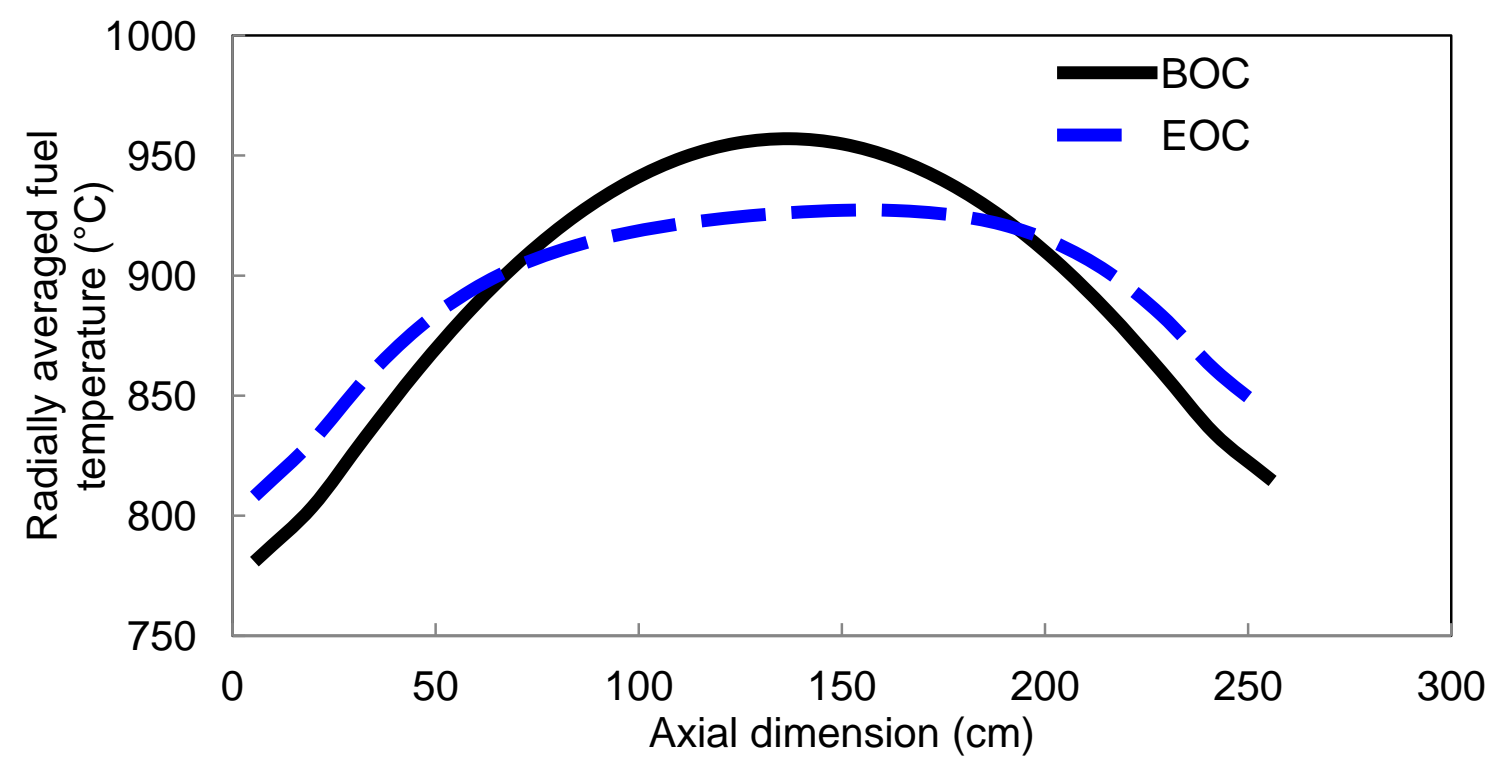

Fig. 16. Radially averaged axial fuel temperature distribution in the FHR DR at BOC and EOC. 


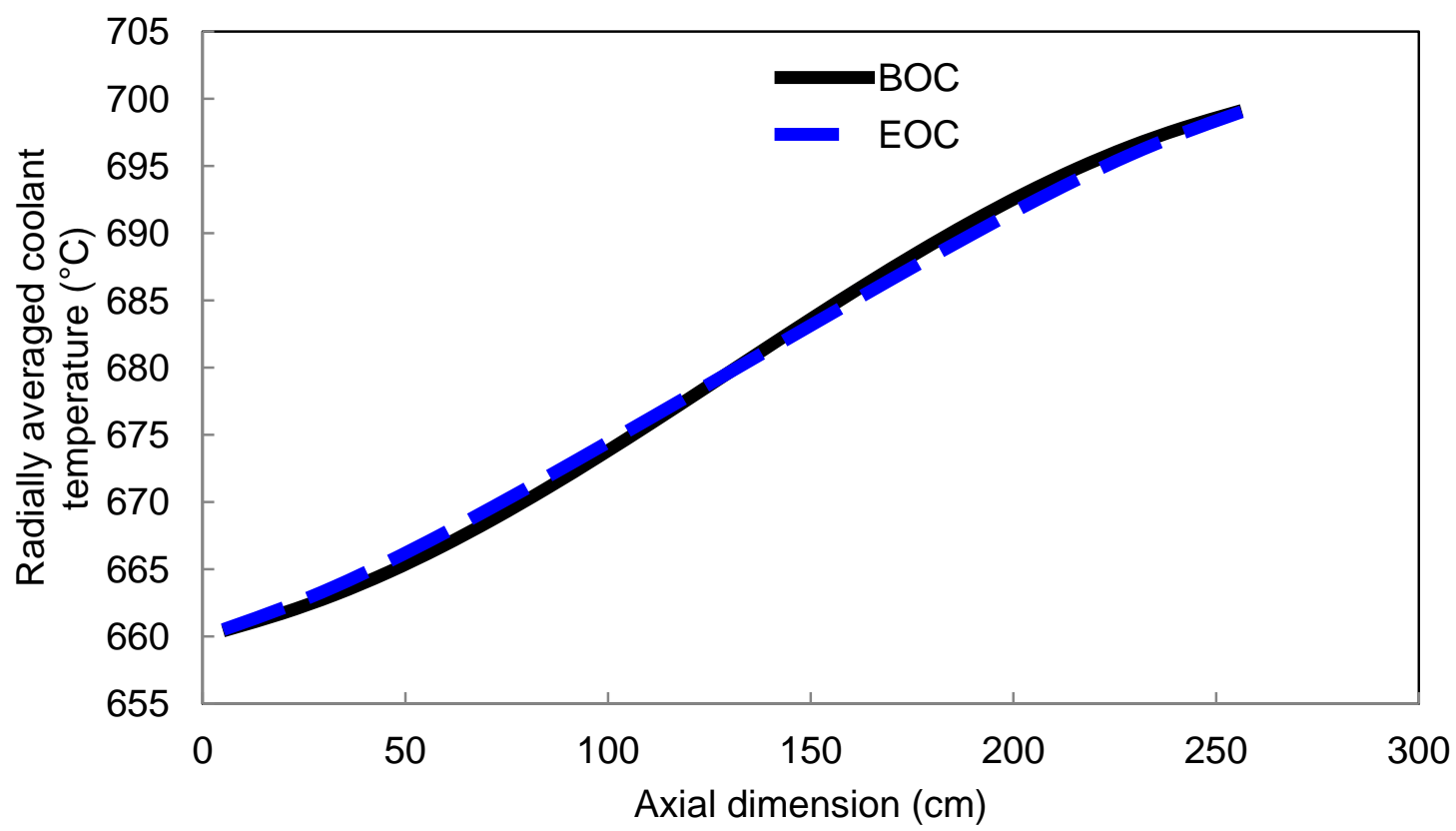

Fig. 17. Radially averaged axial coolant temperature distribution in the FHR DR at BOC and EOC.

\section{Safety Analysis of the FHR DR}

The FHR DR has a variety of safety features, including inherently negative reactivity feedback coefficients and a robust fuel form (TRISO). The well-established tools RELAP5-3D and TRACE were applied in a preliminary safety analysis of the FHR DR. Design and licensing strategies by Scarlat, et al. (2014) provided the basis for selecting the initiating events and transient scenarios studied for the FHR DR safety analysis. Analyses were performed to determine the potential response of the FHR to a variety of anticipated operational occurrences (AOOs) and design basis accident (DBA) events. These AOOs and DBAs included specific realizations of the following example event initiators (Scarlat et al. 2014):

(1) increase in heat removal from the primary coolant, 
(2) decrease in heat removal from the primary coolant,

(3) decrease in reactor coolant system flow rate,

(4) reactivity accidents,

(5) increase in reactor coolant inventory,

(6) decrease in reactor coolant inventory, and/or

(7) radioactive release from a subsystem or component.

Specific example realizations of the events studied included LOFF with SCRAM, LOFF without SCRAM, overcooling transients, and reactivity-initiated accidents at hot full power and hot zero power conditions. Where appropriate, these transients were studied with neutron kinetics reactivity feedback. Although many events were considered, only two example events are presented in this paper: a reactivity accident and a LOFF with SCRAM, selected because the results of these two events provide a reasonable illustration of transient response characteristics.

To provide confidence in the models, rod withdrawal simulations were performed using RELAP5-3D and TRACE models of the FHR DR. A multiple rod withdrawal event at hot full power (HFP) was simulated with RELAP5-3D and TRACE using kinetics feedback to simulate the reactor power over time. A reactivity worth of $0.58 \$$ was used for the inadvertently withdrawn rods, and a Doppler reactivity coefficient of $-0.0043 \$ / \mathrm{K}$. These values were used based on reactor physics calculations for the FHR core. The pumps operated at 100\% flow conditions throughout the event. Simulation results for the HFP rapid multiple rod withdrawal event are shown in Fig. 18. RELAP5-3D predicted a peak power of 229.9 MW during the initial power spike versus a predicted peak power of 219.5 MW in TRACE. Both codes predicted similar behavior and settled to 
essentially the same asymptotic power level afterwards, demonstrating good agreement.
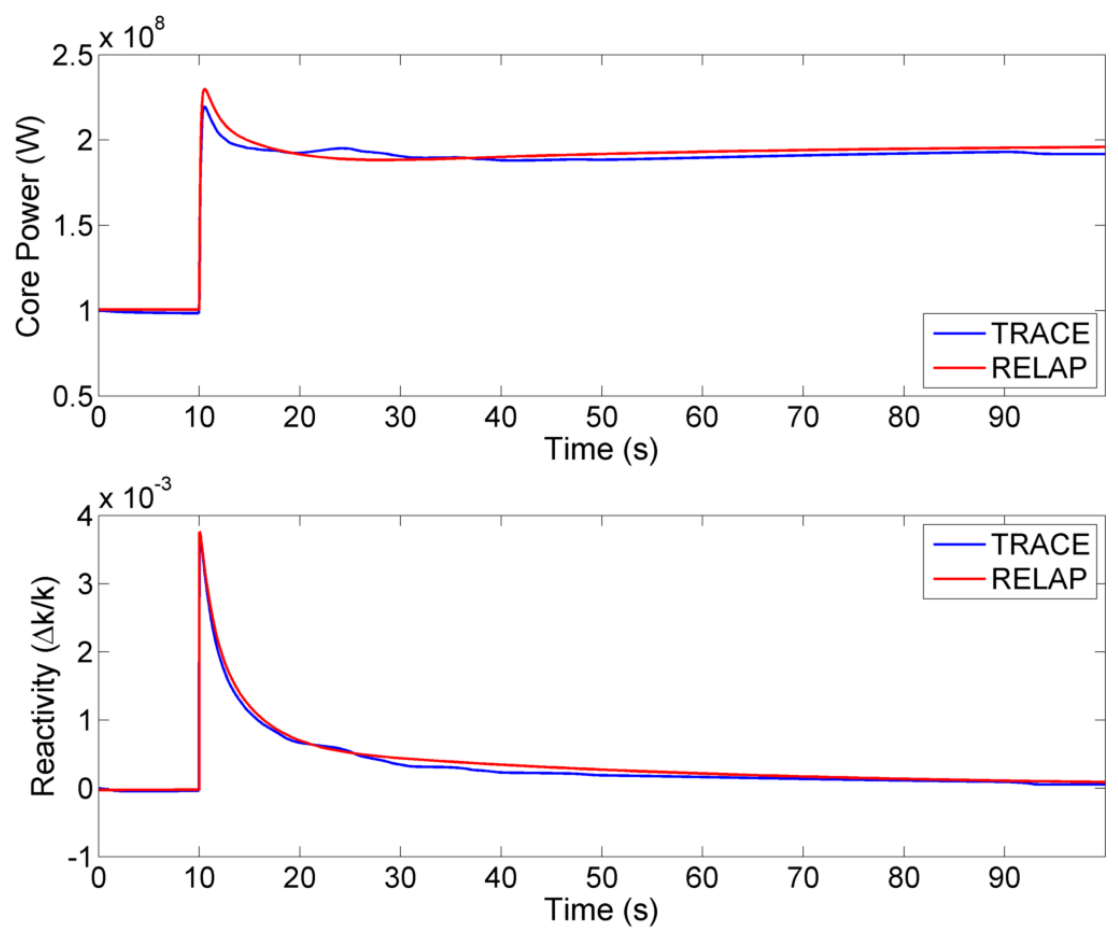

Fig. 18. Comparison of reactor power (top) and reactivity (bottom) calculated by

TRACE and RELAP5-3D for the HFP rapid multiple rod withdrawal event.

Given the nature of the FHR DR (a low pressure system), this rapid (step insertion) multiple rod withdrawal event is not a credible scenario as there is no identified mechanism to cause instantaneous multiple rod withdrawal. However, this event was modeled to demonstrate agreement in the reactivity feedback parameters in the RELAP5-3D and TRACE models. This example demonstrates the capability of both RELAP5-3D and TRACE to provide a simulation of postulated safety events for the FHR DR system with thermal feedback, and it also illustrates how code-to-code comparison studies were leveraged to enhance confidence in the results of the safety analysis. An additional comparison (which is not included in this paper) was conducted for a hot 
zero power super prompt critical reactivity insertion. When compared to a Nordheim-Fuchs analytical solution, the RELAP5-3D and TRACE models showed reasonable agreement between models.

The LOFF transient was evaluated using the RELAP5-3D model, simulated with reactor power falling to decay heat levels. Two cases were considered: 1) the heat was removed by only the passive DRACS, and, 2) the heat was removed by the passive and one active DRACS. A natural convection DRACS flow of $\sim 4 \mathrm{~kg} / \mathrm{s}$ was calculated. The maximum temperature of the primary coolant, which was obtained the case considering only the passive DRACS was calculated to be $770^{\circ} \mathrm{C}$ in the upper plenum occurring at $\sim 10,000 \mathrm{~s}$ into the transient. Coolant temperatures decrease after $\sim 36,000 \mathrm{~s}$ with the passive DRACS, and after 15,000 s with the passive and one active DRACS after the DRACS removes more heat than the core generates. Calculated maximum fuel temperatures are significantly less than $1600^{\circ} \mathrm{C}$. The results for this transient indicate that the passive safety features of FHRs could be demonstrated in a LOFF simulation in the FHR DR. The results of this transient are similar to the previous results for the SmAHTR (Carbajo et al. 2010) for the same transient. This RELAP5-3D model was used to study a variety of safety-related events.

Example transient results from an LOFF transient with SCRAM are shown in Fig. 19. This analysis assumes that one of the active DRACS is inoperable but that the other active DRACS and the passive DRACS are operating. The predicted coolant temperatures during the transient are expected to be acceptable. Benefitting from the low pressure system and the high temperature strength properties of Alloy $800 \mathrm{H}$, the vessel is designed to avoid damage during LOFF or other scenarios. 


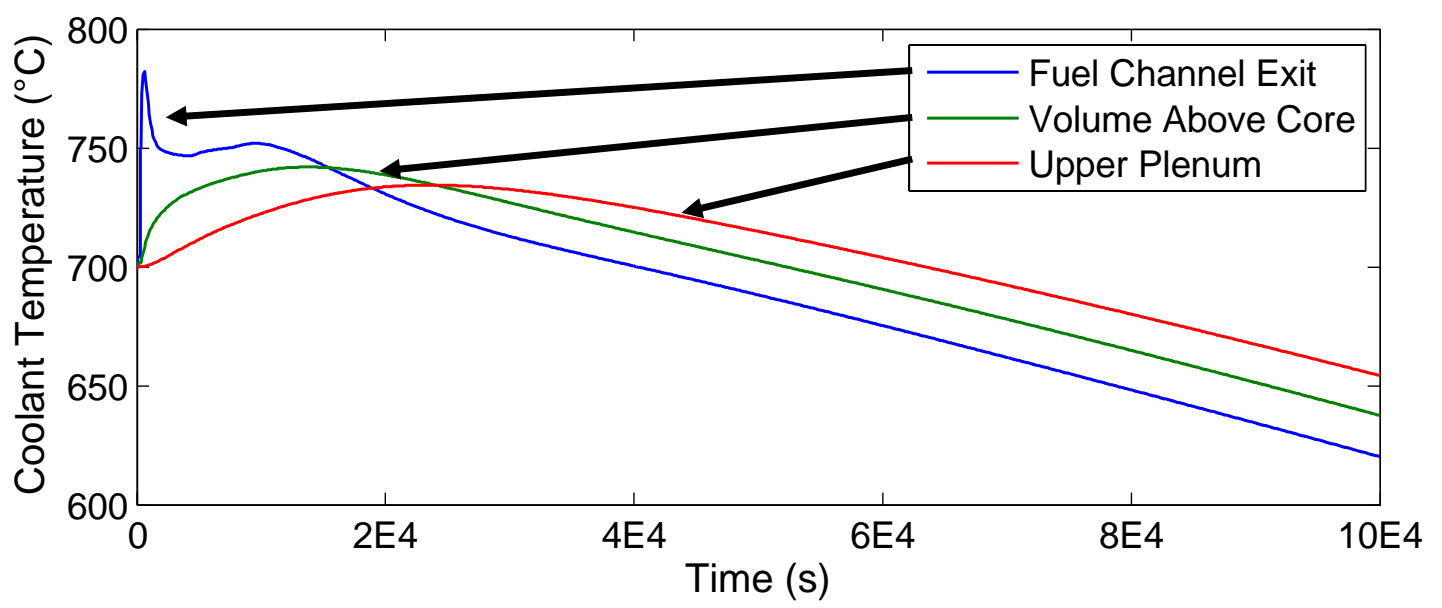

Fig. 19. RELAP5-3D calculated coolant temperatures during a LOFF transient with SCRAM.

\section{Tritium Management in the FHR DR}

FLiBe features relatively attractive coolant properties and is also a neutron moderator. This combination results in coolant temperature and void coefficients that are either negative or negligible, which makes it the coolant of choice for FHR concepts. A challenge with FLiBe coolant is the production of tritium $\left({ }^{3} \mathrm{H}\right)$, a radioactive isotope of hydrogen. An economically attractive and technically viable tritium management solution is necessary for the commercial FHR deployment, and a vital role of the FHR DR is to enable in situ technology readiness level advancement of tritium management technologies. Tritium is produced largely due to radioactive transmutation of ${ }^{6} \mathrm{Li}$, which is an isotope found in the $\mathrm{Li}$ in the salt and can also be produced through beryllium transmutation. The tritium production rate is highest when the concentration of ${ }^{6} \mathrm{Li}$ is highest and initial and equilibrium tritium production rates in an FHR are therefore different. Whether the higher rates occur at equilibrium or during initial operation depends on the initial enrichment of ${ }^{7} \mathrm{Li}$, and the time to equilibrium depends on initial salt properties, reactor flux levels, and overall 
primary salt inventories. The estimated tritium source term (in curies per gigawatt thermal per day) from the FHR DR assuming an initial enrichment of ${ }^{7} \mathrm{Li}$ of $99.995 \%$ is shown in Fig. 20 as a function of possible FLiBe inventories in the primary system.

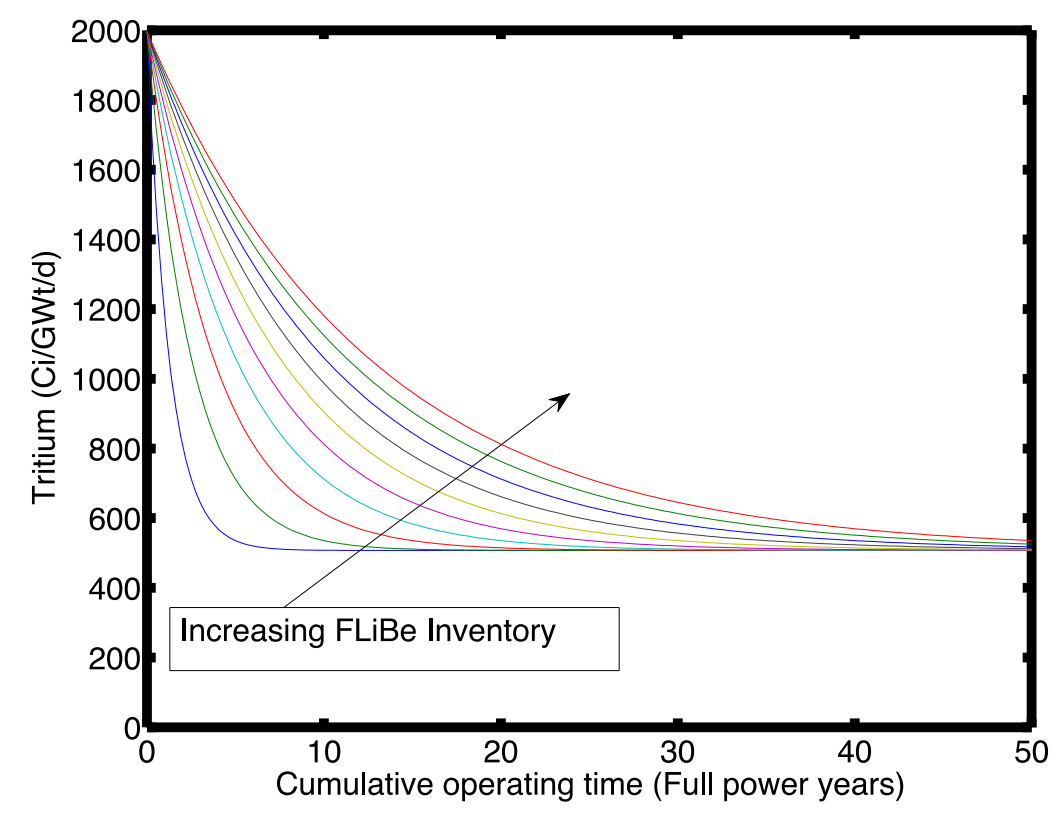

Fig. 20. Tritium source term estimates for the FHR DR design.

To develop bounding estimates on tritium transport, the Tritium Diffusion Evolution and Transport (TRIDENT) code developed at MIT (Stempien et al. 2015, Stempien et al. 2016) was adapted to reflect the characteristics of the FHR DR. A few key parameters of the adapted model include the neutron flux conditions of the reactor and the volume of FLiBe exposed to the core neutron flux (which determines the formation rate of tritium), the volumes and surface areas of graphite (for adsorption and corrosion considerations), and the piping (e.g., heat exchanger) surface area. The FHR DR TRIDENT model was used to investigate the release rate of tritium to the environment and the potential impacts of a tritium capture system on the release rate. Fig. 21 demonstrates the resulting release rates for three example mitigation scenarios. The base case 
tritium release scenario assumes no tritium management, and the other two scenarios assume tritium capture devices (porous carbon bed) with a $1 \%$ and a $10 \%$ replacement rate (RR) per day. All cases assume an 18-month cycle, release to the environment of any tritium that diffuses through the primary piping (i.e., no secondary sweep gases and no containment benefit of the secondary system), and an assumed initial lithium purity of $99.995 \%{ }^{7} \mathrm{Li}$. With respect to the base scenario, with no tritium capture mechanisms considered, the data demonstrate that a tritium capture mechanism is necessary to keep tritium release rates below current regulatory requirements. However, the results from the tritium release scenario with $10 \%$ RR per day of the carbon bed indicate that, provided sufficient investment in research and development, recovery systems with modest online replacement (e.g., the tritium capture material can be removed and replaced with fresh unsaturated material) may eventually be capable of reducing tritium release to levels at or below existing commercial LWRs. For example, the release rate to the reactor coolant system at Watts Bar Unit 1 is approximately $1 \mathrm{Ci} /$ day of direct/soluble tritium (Tennessee Valley Authority 2015). Another estimate of release to the environment for a large LWR with zirconium-based cladding is on the order of 2 Ci/day (Strasser et al. 1982). 


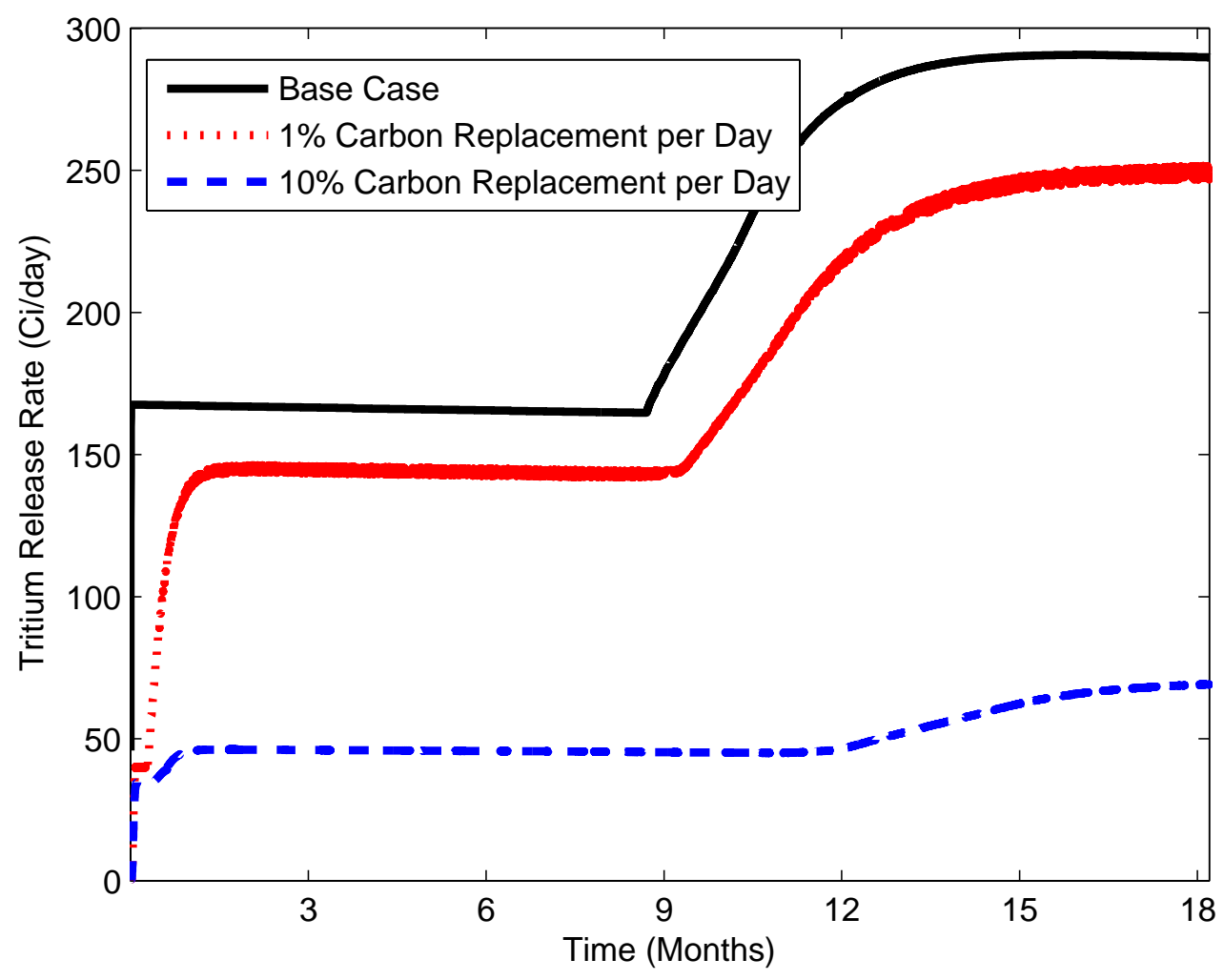

Fig. 21. Example tritium release rate to the environment for several scenarios.

The concept of replaceable gettering materials for tritium management is derived from Stempien, et al. (2015). The approach in Stempien, et al. (2015) was to getter tritium using a packed bed of porous carbon spheres within the primary system outside the reactor core within the hot legs of the primary loop. A fraction of the spheres is periodically removed and heated to drive off the gettered tritium. The preliminary scoping evaluation in this work indicates that, for the FHR DR, the required volume of the gettering material would be large. To improve this concept, a porous carbon form with high tritium gettering capability, large surface area per unit volume, and low flow resistance would be required. Also, methods must be developed to remove this material from the primary salt and regenerate it or replace it with fresh material during operation. 


\section{Summary}

The FHR DR is a preconceptual design for a fluoride salt-cooled engineering demonstration reactor. Neutronic and fuel cycle design calculations were performed using the Serpent Monte Carlo reactor physics tool and the PARCS nodal diffusion tool. Thermal-hydraulic calculations performed with the analysis tools COMSOL and RELAP5-3D were used to determine the potential thermal and hydraulic characteristics of the concept. The TRIDENT code was used for scoping evaluation of tritium transport in the primary loop of the system. These scoping design calculations provide early indication that the FHR DR maintains acceptable performance parameters.

This paper shows the key results from the neutronic and thermal hydraulics design of the core and the primary system. Additionally, results of a preliminary safety analysis of selected design basis accident scenarios indicate that inherent and passive safety characteristics of the system ensure system shutdown and vessel integrity. In addition, the simulation of design basis events described in this paper illustrates how an operating FHR DR might be used to demonstrate the inherent safety characteristics of FHRs. Specifically, these preliminary results indicate that the FHR DR would demonstrate the efficacy of the passive decay heat removal using DRACS, which is a key inherent safety feature in a number of proposed FHR designs.

It is important to note that the FHR DR is at a very early stage of development. The concept was developed as part of the broader U.S. Department of Energy study of advanced demonstration and test reactor options.

\section{Acknowledgements}

This effort was supported by the U.S. DOE-NE in an evaluation of advanced demonstration and 
test reactor concepts utilizing a variety of technology options. We gratefully acknowledge Tom O’Connor (DOE-NE), Jess Gehin (ORNL), Bob Hill (Argonne National Laboratory), and David Petti (Idaho National Laboratory).

The FHR DR effort benefits greatly from the efforts of many individuals and institutions performing research on Fluoride Salt-Cooled High Temperature Reactors. We would like to credit the two Integrated Research Projects funded by DOE-NE led by MIT and Georgia Institute of Technology. Additionally, we acknowledge Charles Forsberg (MIT), Per Peterson (UCB), David Holcomb (ORNL), Joshua Richard (Los Alamos National Laboratory), John Stempien (Idaho National Laboratory), Raluca Scarlat (University of Wisconsin), and Michael Laufer (UCB) specifically for their gracious sharing of information and helpful insights.

Further details about the FHR DR are available in Qualls et al. $(2016,2017)$ and Brown et al. (2016).

Douglas Crawford, Marc-Olivier Delchini, and David Pointer are gratefully acknowledged for their helpful internal review comments.

\section{References}

AREVA NP Inc. "Evaluation of the LS-VHTR Concept," AREVA NP Inc. under BEA Contract No. 00045559, AREVA NP Inc., Lynchburg, VA (2007).

Brown, N. R., Qualls, A. L., Betzler, B. R., Carbajo, J. J., Greenwood, M. S., Hale, R., Harrison, T. J., Powers, J. J., Robb, K. R., “Core Design Characteristics of the Fluoride Salt-Cooled High 
Temperature Demonstration Reactor,” ICAPP 2016: Nuclear Innovation: Inventing the Future of Existing and New Nuclear Power; April 17-20; San Francisco, CA, USA.

Carbajo, J.J. et al. "Transient Thermal-Hydraulic Simulation of the Small Modular Advanced High-Temperature Reactor (SmAHTR)," Trans. Am. Nucl. Society 103, Las Vegas, Nevada (2010).

Carbajo, J. J., Qualls, L., Brown, N. R. “Thermal Hydraulic Design of a Fluoride High-Temperature Demonstration Reactor,” Trans. Am. Nucl. Society 114, New Orleans, Louisiana (2016).

COMSOL Multiphysics Code, website http://www.comsol.com (2015).

Downar, T.J., Barber, D.A., Miller, R.M. et al., 2002. PARCS: Purdue advanced reactor core simulator, In: Proceedings of the International Meeting on New Frontiers of Nuclear Technology: Reactor Physics, Safety and High-Performance Computing (PHYSOR 2002), Seoul.

Forsberg, C., L.-W. Hu, J. Richard, R. Romatoski, B. Forget, J. Stempien, R. Ballinger, K. Sun, and D. Carpenter. Fluoride-Salt-Cooled High-Temperature Test Reactor (FHTR): Goals, Options, Ownership, Requirements, Design, Licensing, and Support Facilities, Massachusetts Institute of 
Technology-ANP-TR-154 (Cambridge, MA: Massachusetts Institute of Technology, December 2014).

Gentry, C., G. I. Maldonado, K. S. Kim. “Development of a Two-Step Reactor Physics Analysis Procedure for Advanced High Temperature Reactors," in Proceedings of PHYSOR 2016: Unifying Theory and Experiments in the $21^{\text {st }}$ Century, Sun Valley, ID, USA (2016).

Greene, S. R., et al. Pre-Conceptual Design of a Fluoride-Salt-Cooled Small Modular Advanced high-Temperature Reactor (SmAHTR), ORNL/TM-2010/199 (Oak Ridge, TN: UT-Battelle, LLC, Oak Ridge National Laboratory, 2010).

Grover, S. Blaine, and David A. Petti. "Status of the NGNP fuel experiment AGR-2 irradiated in the advanced test reactor." Nuclear Engineering and Design 271 (2014a): 238-243.

Grover, S. Blaine, and David A. Petti. "Design and status of the NGNP fuel experiment AGR-3/4 irradiated in the advanced test reactor." Nuclear Engineering and Design 271 (2014b): 142-148.

Holcomb, D. E., F. J. Peretz, and A. L. Qualls. Advanced High Temperature Reactor Systems and 
Economic Analysis, ORNL/TM-2011/364 (Oak Ridge, TN: UT-Battelle, LLC, Oak Ridge National Laboratory, September 2011).

Leppänen, J., 2007. Development of a New Monte Carlo Reactor Physics Code, University of Helsinki, Ph.D. Dissertation, 2007.

Petrovic, B., G. I. Maldonado. Fuel and Core Design Options to Overcome the Heavy Metal Loading Limit and Improve Performance and Safety of Liquid Salt Cooled Reactors. DOE NEUP Project Report 12-3870 (2016).

Petti, D., D. Crawford, and N. Chauvin. "Fuels for advanced nuclear energy systems." MRS bulletin 34.01 (2009): 40-45.

Petti, David, et al. "The DOE advanced gas reactor fuel development and qualification program." JOM 62.9 (2010): 62-66.

Planchon, H. P., Singer, R. M. Mohr, D., Feldman, E. E., Chang, L. K., and Betten, P. R., “The experimental breeder reactor II inherent shutdown and heat removal tests - results and analysis." 
Nuclear Engineering and Design 91, no. 3 (1986): 287-296.

Qualls, A. L., Betzler, B. R., Brown, N. R., Carbajo, J. J., Greenwood, M. S., Hale, R. T., Harrison, T. J., Powers, J. J., Robb, K. R., Terrell, J., Wysocki, A. J., Gehin, J. C., Worrall, A., “Preconceptual design of a fluoride high temperature salt-cooled engineering demonstration reactor: motivation, philosophy, and system design," Annals of Nuclear Energy (2017).

Qualls, A., et al. Fluoride Salt-Cooled High-Temperature Demonstration Reactor Point Design. No. ORNL/TM-2016/85. Oak Ridge National Laboratory (ORNL), Oak Ridge, TN (United States), 2016.

R. Scarlat et al., "Design and licensing strategies for the fluoride-salt-cooled, high-temperature reactor (FHR) technology," Progress in Nuclear Energy 77, pp. 406-420, (2014).

Stempien, J. D., R. G. Ballinger, C. W. Forsberg, “A Model of Tritium Transport and Corrosion in Salt-Cooled Reactors," Transactions of the American Nuclear Society Winter Meeting, 15081, Washington, DC, November 8-12, 2015. 
Stempien, John D., Ronald G. Ballinger, and Charles W. Forsberg. "An integrated model of tritium transport and corrosion in Fluoride Salt-Cooled High-Temperature Reactors (FHRs)-Part I: Theory and benchmarking." Nuclear Engineering and Design 310 (2016): 258-272.

Strasser, A. J., J. Santucci, K. Lindquist, W. Yario, G. Stern, L. Goldstein, and L. Joseph. An Evaluation of Stainless Steel Cladding for Use in Current Design LWRs, NP-2642 (Palo Alto, CA, Electric Power Research Institute, 1982).

Tennessee Valley Authority, letter from TVA to NRC, "Watts Bar Nuclear Plant, Unit 1 Tritium Production Program, Updated Plans for Cycle 13 Operation and Updated Evaluation of the Radiological Impacts of Tritium Permeation into the Reactor Coolant System," January 30, 2015.

U.S. NRC, "TRACE V5.0: Theory Manual," Division of Safety Analysis, Washington DC, 2012.

Wigeland, R., T. Taiwo, H. Ludewig, M. Todosow, W. Halsey, J. Gehin, R. Jubin, J. Buelt, S. Stockinger, K. Jenni, B. Oakley, Nuclear Fuel Cycle Evaluation and Screening-Final Report, INL/EXT-14-31465 FCRD- FCO-2014-000106 (Idaho Falls, ID, Idaho National Laboratory, October 8,2014$)$.

D. F. Williams, L. M. Toth, K. T. Clarno, Assessment of Candidate Molten Salt Coolants for the 
Advanced High-Temperature Reactor (AHTR), ORNL/TM-2006/12, Oak Ridge National Laboratory, Oak Ridge, TN (2006).

Žáková, J., Talamo, A. “Analysis of the reactivity coefficients of the advanced high-temperature reactor for plutonium and uranium fuels." Annals of Nuclear Energy 35, no. 5 (2008): 904-916. 